\title{
Article \\ Feasibility Assessment of a Dual Intake-Port Scroll Expander Operating in an ORC-Based Power Unit
}

\author{
Fabio Fatigati *(D), Giammarco Di Giovine $(\mathbb{B})$ and Roberto Cipollone $(\mathbb{C}$ \\ Department of Industrial and Information Engineering and Economics, University of L'Aquila, Piazzale Ernesto \\ Pontieri, Monteluco di Roio, 67100 L'Aquila, Italy; giammarco.digiovine@graduate.univaq.it (G.D.G.); \\ roberto.cipollone@univaq.it (R.C.) \\ * Correspondence: fabio.fatigati@univaq.it; Tel.: +39-0862-434349
}

\section{check for}

updates

Citation: Fatigati, F.; Di Giovine, G.; Cipollone, R. Feasibility Assessment of a Dual Intake-Port Scroll Expander Operating in an ORC-Based Power Unit. Energies 2022, 15, 770. https:// doi.org/10.3390/en15030770

Academic Editors: Francesco Calise, Neven Duić, Maria da Graça Carvalho, Qiuwang Wang, Poul Alberg Østergaard and Adrián Mota Babiloni

Received: 9 December 2021

Accepted: 19 January 2022

Published: 21 January 2022

Publisher's Note: MDPI stays neutral with regard to jurisdictional claims in published maps and institutional affiliations.

Copyright: (c) 2022 by the authors. Licensee MDPI, Basel, Switzerland. This article is an open access article distributed under the terms and conditions of the Creative Commons Attribution (CC BY) license (https:// creativecommons.org/licenses/by/ $4.0 /)$.

\begin{abstract}
The main driver of research in the road transportation sector is almost certainly the development of technologies which allow for the reduction of $\mathrm{CO}_{2}$ emissions from internal combustion engines (ICEs). Wasted heat recovery (WHR) from the exhaust gases of ICEs based on organic rankine cycle (ORC) power units is one of the most promising technological solutions. However, several issues are raised when the recovery unit is scaled down to small applications, not to mention the fact that thermal sources are characterized by their intrinsically transient nature, as is the case with ICEs. In fact, this leads the ORC unit having to work frequently in off-design conditions. To successfully overcome this issue, the proper design and selection of the expanders are crucial. They are generally chosen from volumetric-type machines, thanks to their capacity to deal with time-varying thermo-fluid dynamic inlet properties. Among them, scroll machines represent one of the best solutions, despite them not yet being optimized as expanders, with them having been studied more as compressors. Dual-intake-port (DIP) technology is a novel solution used to enhance the performance of scroll machines. The effectiveness of this technology was assessed thanks to a comprehensive, experimentally-validated theoretical model of the scroll. It demonstrated that DIP technology can produce a $25 \%$ increase in mechanical power with respect to the baseline machine, without modifying the in-out pressure ratio. Maintaining a constant pressure difference across the expander at 5.6 bar, the power grew from $1131 \mathrm{~W}$ to $1410 \mathrm{~W}$ with the adoption of DIP technology. This power boost is lower than that achieved with a comparable DIP sliding rotary vane expander (SVRE) already studied by the authors, but the DIP Scroll achieved a higher efficiency (50-60\%) when compared to the DIP SVRE case $(40 \%)$.
\end{abstract}

Keywords: waste heat recovery (WHR); organic rankine cycle (ORC); dual intake port scroll expander; fluid-dynamic model; theoretical characterization of scroll expander; model-based design

\section{Introduction}

\subsection{Small Scale ORC-Based Power Unit for Waste Heat Recovery Applications}

The reduction of the pollutant emissions of internal combustion engines (ICEs) represents the driver of research in the road transportation sector. With regard to $\mathrm{CO}_{2}$, the sector is currently responsible of $20 \%$ of the entire amount emitted into the atmosphere [1,2]. Thus, to reduce the environmental impact of this sector, international governments and organizations provide strict limitations on many energy-related engineering sectors. The path to the decarbonization is, in particular, very severe: for a medium-class segment B vehicle, $95 \mathrm{gCO}_{2} / \mathrm{km}$ is the present limit, whereas in 2025 and 2030, further reductions equal to $15 \%$ and $37.5 \%$ (relative to 2021 limits), respectively, will be imposed [3]. Compliance with the reduction is considered so important that in the European context a fee (95 Euros) must be paid by the vehicle manufacturer for each newly registered vehicle and for any fleet-averaged grams of $\mathrm{CO}_{2}$ exceeding the prescribed limitation [3]. This value participates to define the target cost of green technologies in ICE sector, not yet sufficiently estimated 
or considered. Vehicle electrification and hybridization will certainly play a fundamental role in making the transportation sector more environmentally sustainable concerning the $\mathrm{CO}_{2}$ issue. However, this depends on the presence of "green" electricity from the grid: too many geographical areas are still fed with coal-based electricity and this sensibly decreases the real contribution of electrification in terms of $\mathrm{CO}_{2}$ reduction [4]. This issue must be seriously considered, especially in a world which is going through electrification on a huge scale.

Thus, in such a transition period, a key role will be played by technological improvements to ICEs. Among the range of interventions proposed to improve engine efficiency, such as the reduction of vehicle propulsion power and the introduce of eco-driving systems, among others, waste heat recovery (WHR) from exhaust gases through ORC-based power units is one of the most promising solutions [5,6]. Indeed, roughly $35-40 \%$ of fuel chemical energy is lost via exhaust gases. Thus, the recovery of even few percentage points of the wasted heat into mechanical energy is worthy of attention [7]. Nevertheless, the full development of this technology on the market has been delayed by several issues: the increase of engine back-pressure caused by the heat recovery vapor generator (HRVG), not to mention the increase in weight produced by the recovery unit and the limitations of on-board available space, are well known limiting factors [8] which should be addressed with more attention. Another aspect that makes this application challenging is related to the intrinsic transient conditions of the heat source (exhaust gases), which leads the ORC-based unit having to operate in strong off-design conditions [9]. Thus, besides the development of a robust and reliable control system [10], it is fundamental that the components of the recovery unit are properly chosen and designed to ensure operating flexibility [11]. The expander is certainly a key component from this point of view [12]. Specifically, its capability to properly operate outside of the design conditions is particularly appreciated, enabling the recovery unit to tackle the situations produced by a HRVG which operates with a thermal power significantly lower or greater than the design datum. For instance, mixtures of dry and wet working fluid are frequent when the thermal power to be recovered is reduced (as a result of either low engine load or low operating engine speed). For small scale ORC-based units fed by ICE exhaust gases, volumetric expanders are generally preferred to dynamic machines, due to their much lower revolution speed and their capability to deal with flow rates and working fluid property variations [13].

\subsection{Design and Technological Improvement of Scroll Expanders}

In the framework of volumetric expander technologies, a scroll expander is a technology which allows for very high efficiencies at the same time as offering a compact and flexible design [14]. Moreover, it is characterized by a simple manufacture process, a low weight and speed and it tolerates two-phase fluids [15].

Thanks to the potential of scroll technologies, over the last decade an effort has been performed by the scientific community to characterize the performances of scroll expanders for micro and small ORC applications. Although they are a mature technology compared with screw, vane and piston expanders and have good performances for a wide range of operating conditions [16], the development of commercial scroll expanders is still at an early stage and requires more refined mathematical models to further optimize their design as expanders [17]. Besides experimental analysis, many theoretical models of scroll machines have already been developed following different approaches to predict their performance in a wider operating range. In [18], a CFD analysis on two scroll expanders with different built-in volume ratios showed the positive effect of enhanced involute scroll wrap on suction losses, while in [19], the performances of scroll expanders with variable wall thicknesses for high pressure ratio applications were investigated through a validated CFD model. Instead, in [20] a quasi-dimensional numerical model was presented for the purpose of simulating the working process of a scroll expander operating with compressed air: the results indicate that an optimal pressure ratio for each scroll expander exists, which must be considered in the design phase along with clearance size and the scroll 
vane height to pitch ratio. Semi-empirical models have also been released [21], and these have been improved with suitably defined empirical correlations of clearance and friction coefficients [22].

Despite the noteworthy advantages of scroll expanders, this technology still presents huge room of improvement. Indeed, in most applications, scroll expander are generally derived from reversed compressors. This means that scroll machines are often not conceived to work as expanders, with a consequent limit on their efficiency. Therefore, their performance can be improved if the machine is directly designed to work as an expander. To answer to this requirement, several innovative design solutions for scroll expanders have already been developed in the literature.

In [23], a symmetric discharge structure was proposed for scroll machines. The results show that the new configuration allows for the reduction of the discharge pressure, leading to a more uniform flow distribution in the backpressure and discharge chambers, thus enhancing the driving moment and positively affecting the machine's performance. In [24], a novel open-drive scroll expander was designed and tested in a small scale ORC engine operating in low load conditions, showing higher performances when compared with standard converted scroll expanders. Similarly, in [25], a newly designed open-drive oilfree scroll expander was tested and a semi-empirical model was developed to predict the performance of the expander. To develop a generic tool for the design of scroll expanders, a comprehensive algorithm capable of obtaining efficient scroll geometries for any ORC specifications, including the effect of the working fluid selection, was developed in [26]. These effects were also investigated experimentally in [27] by comparing two typical working fluids, outlining several optimization criteria for ORC scroll expanders. In [28], several scroll expander geometries using unconventional scroll profiles and scroll tip shape variations were discussed. It was found that scroll expanders with scrolls of variable wall thicknesses allow for the increase of the geometric expansion ratio without increasing the length of the scroll profiles, and thus avoiding the decrease in efficiency typical of constant wall thickness profiles; this feature is particularly useful for ORC systems as well as for refrigeration cycles and other power cycles where a high-pressure ratio enables higher performances. The same authors extensively studied the positive effects of a variable wall thickness scroll in $[19,29,30]$ using a CFD modeling approach.

One of the main limits of a scroll expander is its fixed displaced volume. This can introduce a penalization when it comes to the performance of the expander, induced by variations in the mass flow rate of the working fluid. In fact, if a volumetric machine is adopted, the raise of mass flow rate produces a quite linear increase of intake pressure [31]. If this intake pressure increases too much, it causes the efficiency of expander to decrease and means that the components must withstand higher mechanical stresses. Moreover, in these circumstances the intake pressure at the expander becomes close to the maximum pressure of the unit which must stay close to the design value due to the implications this has on the thermodynamic cycle. In reality, the only way of mitigating this is to enhance the revolution speed. However, this action leads to the growth of friction losses, thus affecting the whole efficiency of the machine. Flow rate increase, on the other hand, is the correct way to recover more thermal energy from the hot source; in fact, when the power increases, an increase of the flow rate is the only way to keep the thermodynamic properties of the cycle (and of the inlet and outlet sections of all the components of the plant) close to the design values.

Hence, a novel approach to limit the intake pressure increase when a higher mass flow rate enters the expander is presented here for scroll expanders. This is based on the introduction of the dual-intake-port (DIP) technology. This technology involves introducing a further intake port placed after the main one and in correspondence of the expansion phase. Thanks to this approach, the machine becomes more permeable and a higher mass flow rate can be enabled, thus maintaining the intake pressure of the expander. 
This novel technology has already been conceived, developed and characterized by the authors in the context of sliding rotary vane expander machines (SVRE) [31,32]. In this research, the extent to which DIP technology allows for increasing the expander operability was experimentally and theoretically assessed. Indeed, keeping constant the pressure ratio across the machine (and also the intake inlet pressure), the dual intake port in SVREs allows for a higher mass flow rate, producing up to a $50 \%$ increase in the thermal power recoverable from the hot source. This allows for the widening of the expander's operability mainly in the context of hot-source variations, such as in the case of, for instance, ICEs.

Therefore, the aim of the present work was the assessment of the feasibility of a DIP technology, also in the context of scroll expanders, demonstrating the validity of such a novel solution for other volumetric expanders. This was not a straightforward analysis, for it considered the complex fluid-dynamic phenomena taking place inside this machine during intake, expansion and exhaust. Thus, to perform a consistent evaluation, a comprehensive numerical model of the scroll was developed and validated with experimental data. Once the model was experimentally validated, it was used as a design software platform for purposes of evaluating the benefits of a DIP technology, for suitably designing the position of a second intake port and discussing how this port can be realized. Finally, the performances obtained with the DIP in scroll expanders were compared with those obtained with SVREs, thus widening the preliminary analysis performed in [33,34]. In fact, this work constitutes the first comprehensive overview of the benefits of this technology for both types of expanders (and in general in positive displacement machine).

The approach followed is represented by the flow chart in Figure 1:

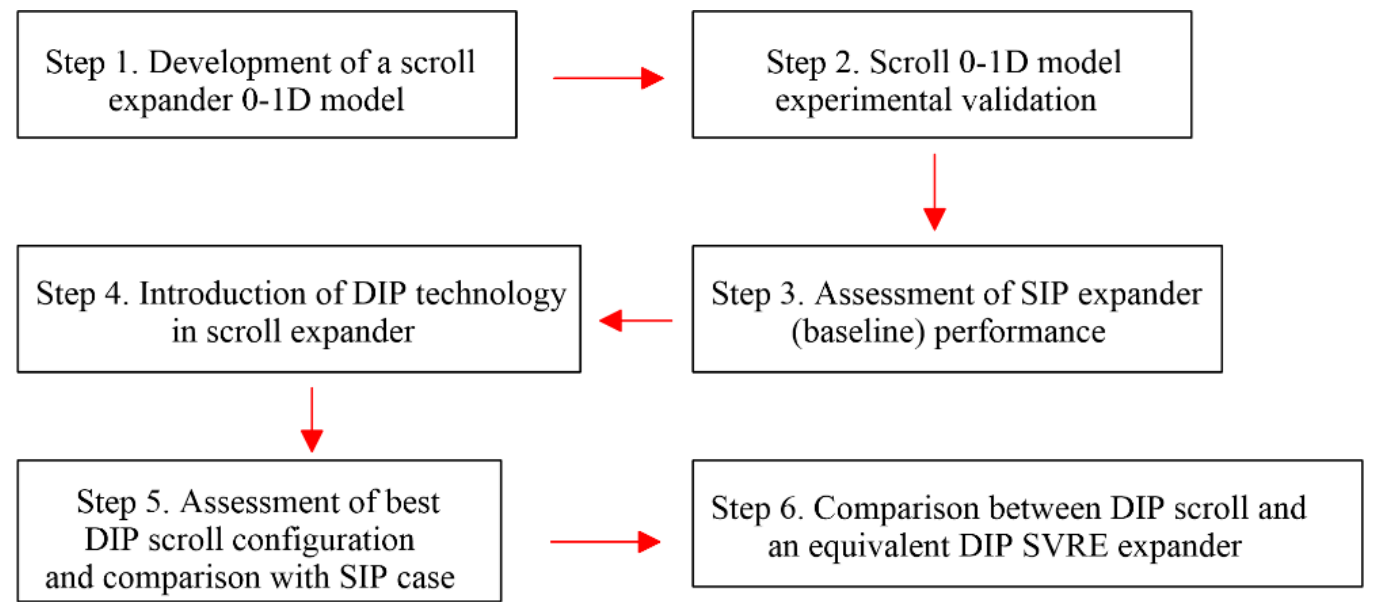

Figure 1. Approach followed for the feasibility assessment of DIP scroll expander technology.

\section{Materials and Methods}

\subsection{Case Study}

A scroll machine consists of a stationary and an orbiting scroll, assembled with a phase difference equal to $180^{\circ}$ (Figure 2a). Considering the expander mode of operation, the expanding fluid moves from the high-pressure chamber (positioned at the center of the scrolls) towards the intermediate and low pressure chambers (shifted gradually towards the external circumference of the machine), spinning the orbiting scroll, and thus producing mechanical power available to the corresponding shaft. The ideal contact points between orbiting and stationary scrolls define the working volumes, whose pressure varies according to the overall pressure gradient. Each rotation of the orbiting scroll moves the fluid towards the subsequent volume at lower pressure. Therefore, the number of rotations required to completely expand one volume of aspired fluid depends on the number of scroll windings. 


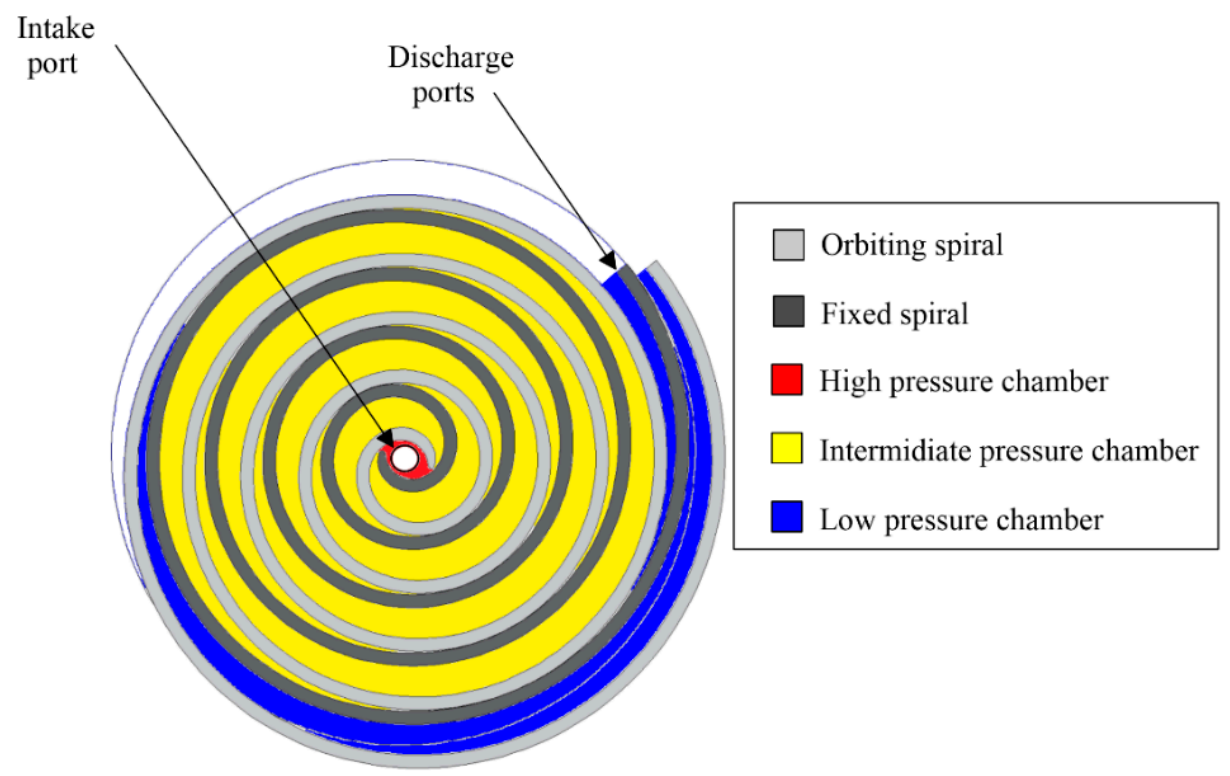

(a)

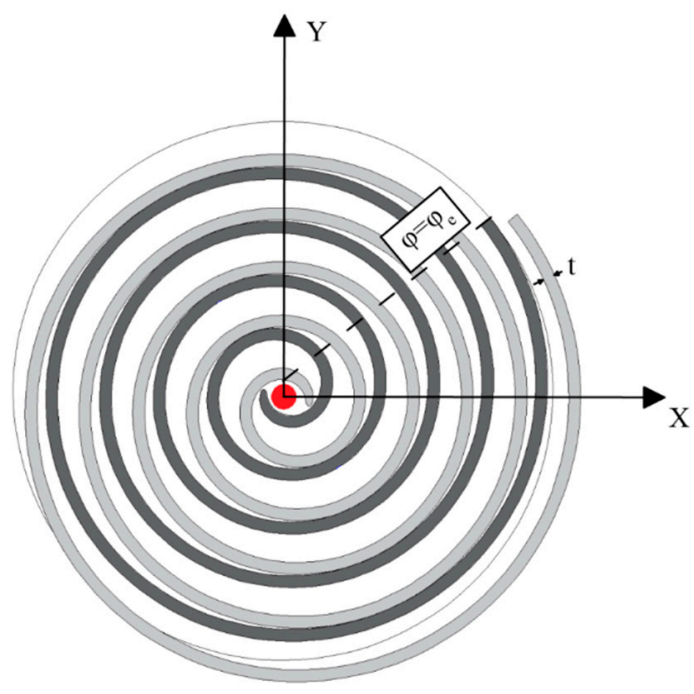

(b)

Figure 2. (a) Representation of the stationary and orbiting scrolls and the chambers identified during the expansion process [35]; (b) main parameters of a scroll geometry, composed of inner and outer involutes spaced away from each other by a specific distance $t[36]$.

The scroll expander considered in this work was previously studied in [35]. It was originally an oil-free open-drive air scroll compressor, characterized by a large built-in volume ratio (close to 4.0) and a swept volume equal to $148 \mathrm{~cm}^{3}$ in compressor mode. This scroll machine was studied in expander mode by simply exchanging the suction with the discharge port. Therefore, the suction occurs axially, while the discharge takes place circumferentially: in this way, the chambers identified by the scrolls increase their volume during the expansion process. Moreover, it requires approximately five revolutions of the orbiting scroll to completely expand one volume of aspired fluid.

The geometry of each scroll is defined by two involutes that develop around a common basic circle with a radius $r_{\mathrm{b}}$ [36], spaced away from each other by a distance $t$ (Figure $2 b$ ). The main parameters defining the geometry of the scroll expander considered in the current application are reported in Table 1. Further geometrical details, including the geometry of the suction and discharge pipes, are described in [35]. 
Table 1. Geometrical parameters of the scroll expander [35].

\begin{tabular}{cccc}
\hline Description & Abbreviation & Value & Unit of Measurement \\
\hline Radius of the basic circle of the scroll & $r_{\mathrm{b}}$ & 3.3 & {$[\mathrm{~mm}]$} \\
Heigh of scroll vanes & $h$ & 28.7 & {$[\mathrm{~mm}]$} \\
Initial angle of the outer involute & $\varphi_{\mathrm{o}, 0}$ & 0 & {$[\mathrm{rad}]$} \\
Initial angle of the inner involute & $\varphi_{\mathrm{i}, 0}$ & 1.4 & {$[\mathrm{rad}]$} \\
Starting angle of the outer involute & $\varphi_{\mathrm{o}, \mathrm{s}}$ & 1.6 & {$[\mathrm{rad}]$} \\
Starting angle of the inner involute & $\varphi_{\mathrm{i}, \mathrm{s}}$ & 3.5 & {$[\mathrm{rad}]$} \\
Involute ending angle & $\varphi_{\mathrm{e}}$ & 27.4 & {$[\mathrm{rad}]$} \\
Orbiting radius of the rotating scroll & $r_{\mathrm{o}}$ & 5.7 & {$[\mathrm{~mm}]$} \\
Scroll vane thickness & $t$ & 4.6 & {$[\mathrm{~mm}]$} \\
Discharge angle & $\theta_{\mathrm{d}}$ & 3.9 & {$[\mathrm{rad}]$} \\
\hline
\end{tabular}

\subsection{Numerical Model}

Scroll machines have been studied as scroll compressors in refrigeration applications. Comprehensive simulation models [36,37], as well as CFD models [38], have been developed for their optimization. Similarly, analytical [21,39] and numerical [19] models for scroll expanders have been studied, due to interest in their WHR-ORC applications.

In this work, the scroll expander was modeled using the GT-SUITE ${ }^{\text {TM }}$ software, which allows for the integration of a mono-dimensional (1-D) and zero-dimensional (0-D) thermofluid-dynamic analysis. The 1-D analysis is performed to model the intake and exhaust phases, during which the working fluid is characterized by transient phenomena. Therefore, the intake and exhaust pipes can be discretized into a series of volumes, and for each subvolume Navier-Stokes equations are solved [40]. The differential equations were solved using an explicit Euler scheme, where the primary solution variables were mass flow rate, density and internal energy.

Concerning the 0-D approach, this was adopted to reproduce the chamber filling and emptying phases, as they are modeled as lumped volumes whose variation is driven by the revolution angle of the machine. In light of this approach, the scroll chambers could be represented as two symmetrical sequences of lumped volumes ( $a, b$ in Figures 3 and $4 a)$ with the same time, and consequently, angular progression. The volumes of one sequence were $360^{\circ}$ phase shifted, because each of them was generated by the previous one for each rotation of the orbiting scroll.

This concept also formed the basis of the modeling of scroll machines in the developed software platform, where fluid dynamic and mechanical problems were analyzed separately. In fact, the flow inside the scroll expander evolved according to a sequence of properly linked pipes, plenums and expanding chambers. Instead, the physical and geometrical properties of the machine were defined by linking the chambers properly to the scroll shaft (element 10 of Figure 3), which was ideally divided into two parts for each symmetrical sequence of volumes.

The theoretical model of the ORC scroll expander is represented in Figure 3. The elements numbered (1) and (7) identify the in-out flow boundary conditions in terms of pressure and temperature, while the elements indicated as (11) impose the speed to the orbiting scroll shaft. The fluid flows from the inlet boundary condition (1), through inlet pipes (2), towards the suction plenum (3), which distributes it to the expansion chambers (4): these are identified by the ideal contact points between orbiting and stationary scrolls, in this case five chambers for each of the two symmetrical volume sequences (Figure 4a). Subsequently, the discharge plenum (5) collects the fluid coming out of the expansion chambers, driving it to the outlet boundary (7) through the outlet pipes (6).

Further considerations are necessary to explain the connections between the chambers.

Firstly, in the theoretical model, the real volume sequence is modeled by connecting each chamber with the suction-discharge plenums and the scroll shaft (10). In fact, this latter gives to each chamber the same geometry (in terms of angular progression of volume, of intake and exhaust port areas, as well as the shaft speed of the orbiting scroll). Moreover, 
the phasing between consecutive chambers is realized by the link sequence between each of them and the scroll shaft (10). Therefore, the connection of each chamber with the suction and discharge plenums is required. Furthermore, this template assumes a $360^{\circ}$ period for the angular progression of the chamber geometrical characteristics: thus, an angular scaling factor equal to 0.2 needs to be applied to the effective angular progressions, with five revolutions of the orbiting scroll being necessary to complete a single expansion cycle.

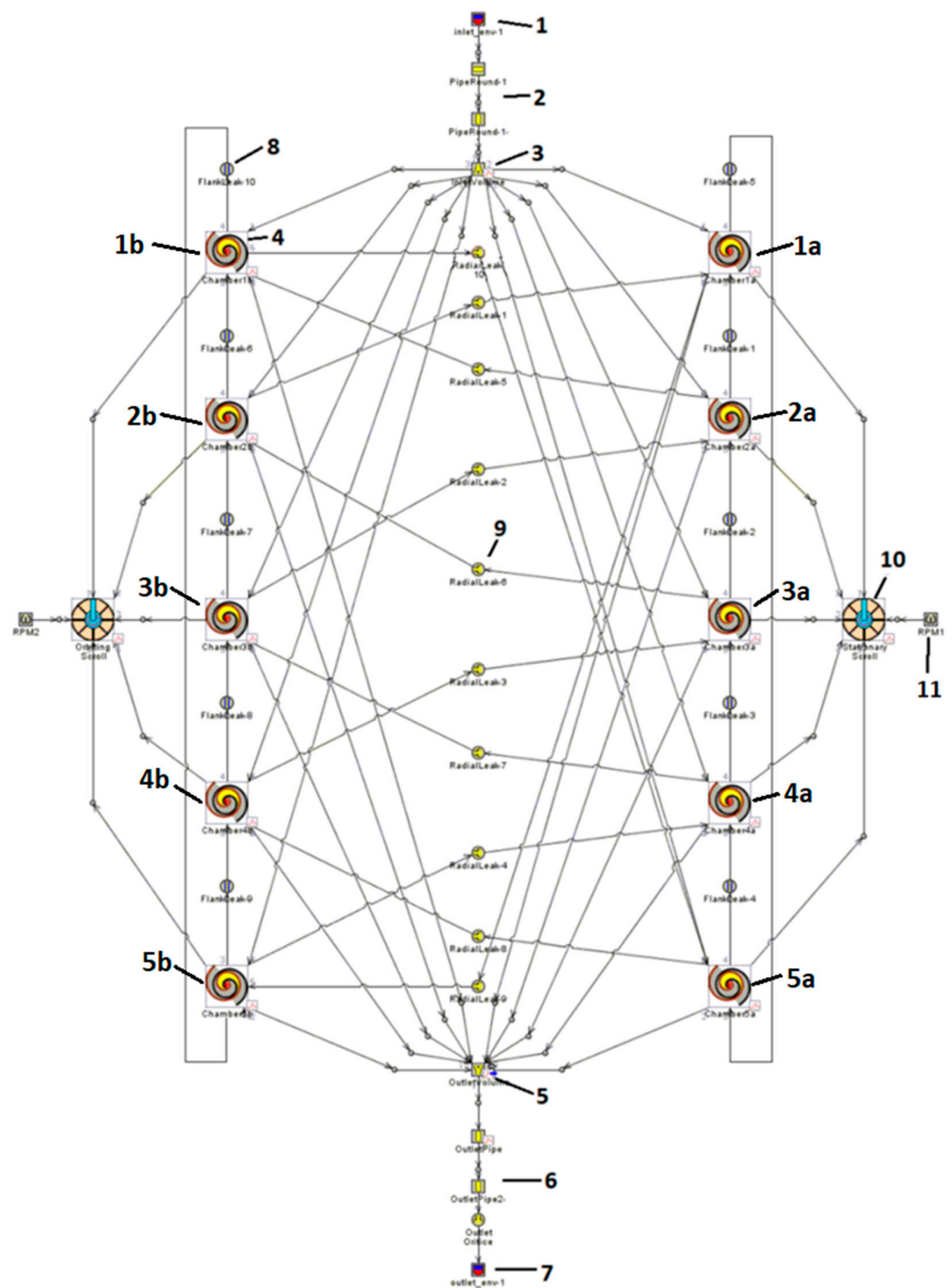

Figure 3. Numerical model of the scroll expander in the GT-SUITE ${ }^{\mathrm{TM}}$. The model block diagram considers two leakage flow paths between adjacent chambers, i.e., flank leakage and radial leakage. 


\section{Legend}

\begin{tabular}{|l|}
\multicolumn{1}{c}{ Legend } \\
$\square$ Fixed spiral $\square$ Orbiting spiral \\
\hline
\end{tabular}

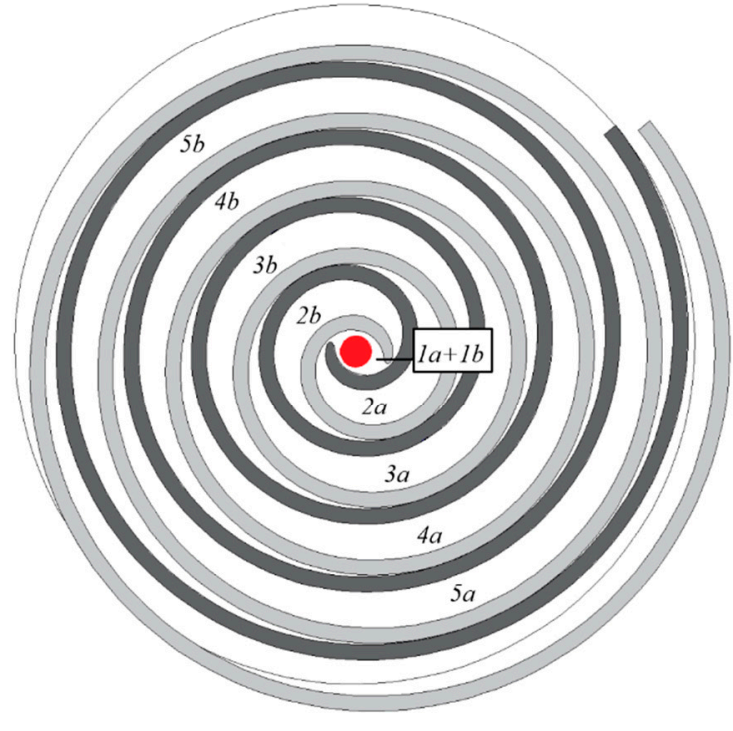

(a)

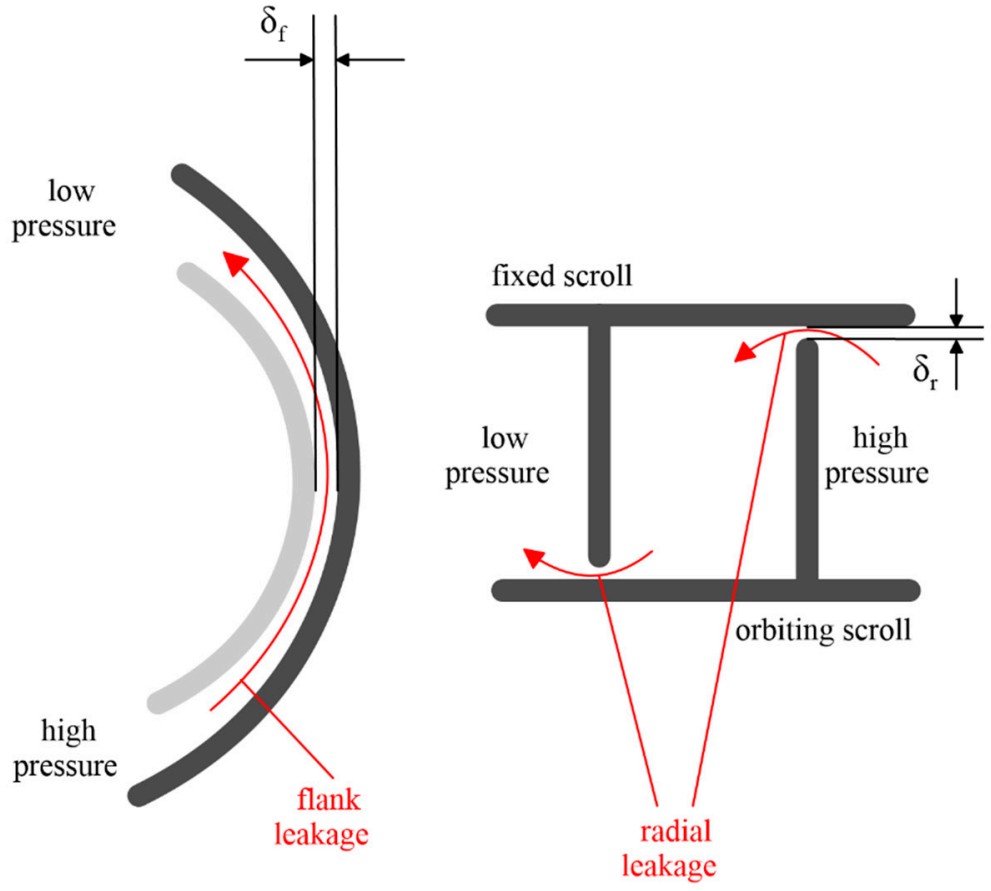

(b)

Figure 4. (a) Definition of the expander working chambers: the fluid expands simultaneously in two symmetrical volume sequences (indicated by the subscripts a and b); (b) flank leakage and radial leakage in scroll expanders. The flow leakages were identified according to the approach of $[35,36]$.

Secondly, the leakage flows induced by the pressure gradient inside scroll machines can be distinguished in terms of flank and radial leakages (Figure $4 \mathrm{~b}$ ). Flank leakages occur between consecutive chambers of the same sequence of volumes because the clearance $\delta_{\mathrm{f}}$ exists between the walls of stationary and orbiting scrolls. Radial leakages, on the other hand, occur between adjacent chambers because the clearance $\delta_{\mathrm{r}}$ exists between the tip of the wall of one scroll and the plate of the other.

These leakages are represented in the model through equivalent templates. Specifically, referring to Figure 3, the flank leakage is represented by an equivalent rectangular flow (8), while the radial leakage is represented by an equivalent orifice (9). Therefore, as an example, the chamber $2 \mathrm{a}$ is linked with the chambers 1a and 3a through a flank leakage element and is linked with the chambers $1 \mathrm{~b}$ and $3 \mathrm{~b}$ through a radial leakage element. This can also be observed in Figure 4a by imagining that the chambers are connected to each other through flank and radial clearances, as shown qualitatively in Figure $4 \mathrm{~b}$.

The case study considered presents tip seals to prevent radial leakages. These moving seals are embedded in a groove at the tip of each scroll, and they extend along all the tip walls, except for a small angle during the suction process. Thus, the equivalent orifice (9) in Figure 3 is considered completely sealed, and therefore the leakages through these clearances were neglected. Instead, the radial leakage that occurs during the suction process was considered to be a factor which modified the angular progression of the suction port area.

Moreover, the mechanical coupling between orbiting and stationary scrolls determines no contact between them, with this specific scroll machine being an oil-free open-drive 
one. Therefore, the flank leakage was tuned to validate the volumetric performance of the model as reported in the validation section.

The useful power is defined as the difference between the indicated power $P_{\text {ind }}$ and the power lost due to friction effects, $P_{\text {loss }}$. The indicated power is evaluated as the area of the indicated diagram which represents the pressure inside the chambers as a function of the volume. Besides the power evaluations, the indicated diagram is fundamental when it comes to assessing the intimate behavior of the machine.

Concerning the power lost due to friction, this can be evaluated once the geometry of the scroll expander is defined. Nevertheless, due to the complex mechanical interactions taking place inside this machine, a physical model of the power lost due to friction was not available. Thus, following the approach generally adopted in the literature [35], the mechanical power lost was defined by tuning the friction torque during the experimental validation.

Therefore, with the overall pressure difference, the inlet fluid temperature and the speed of the orbiting scroll provided as inputs, the model calculates the effective flow rate and outlet temperature of, as well as the power produced by, the expander.

\subsection{Validation}

The model was validated considering the results of the experimental activity performed in [35] on the scroll machine test case. In Table 2, the experimental results show the wide operating range covered by the machine. In fact, the expander intake pressure varies from 5.5 bar to $11.1 \mathrm{bar}$, with the intake temperature ranging from $109.8^{\circ} \mathrm{C}$ to $141.2^{\circ} \mathrm{C}$. The exhaust pressure is low, as it never exceeds 2.1 bar. The mass flow rate elaborated by the machine $\dot{m}_{\mathrm{wf}}$ is comprised within $0.046 \mathrm{~kg} / \mathrm{s}$ and $0.086 \mathrm{~kg} / \mathrm{s}$, producing a mechanical power comprised between $382 \mathrm{~W}$ and $1820 \mathrm{~W}$. Concerning volumetric efficiency (Equation (1)), it assumes very high values, as the minimum value is equal to 0.77 and the maximum one is 0.93 .

$$
\begin{gathered}
\eta_{\mathrm{vol}}=\frac{\dot{m}_{\mathrm{vane}}}{\dot{m}_{\mathrm{wf}}} \\
\eta_{\exp }=\frac{P_{\mathrm{m}}}{\dot{m}_{\mathrm{wf}}\left(h_{\mathrm{in}}-h_{\mathrm{out}, \mathrm{is}}\right)}
\end{gathered}
$$

Table 2. Experimental database for model validation [35].

\begin{tabular}{cccccccc}
\hline Case & $\mathbf{1}$ & $\mathbf{2}$ & $\mathbf{3}$ & $\mathbf{4}$ & $\mathbf{5}$ & $\mathbf{6}$ & $\mathbf{7}$ \\
\hline$p_{\text {in }}[\mathrm{bar}]$ & 6.4 & 5.5 & 8.1 & 8.9 & 11.1 & 7.9 & 9.6 \\
$T_{\text {in }}\left[{ }^{\circ} \mathrm{C}\right]$ & 109.8 & 121.0 & 136.5 & 130.3 & 141.2 & 132.5 & 138.9 \\
$p_{\text {out }}[\mathrm{bar}]$ & 1.9 & 2.0 & 2.1 & 1.7 & 2.0 & 1.8 & 2.1 \\
$T_{\text {out }}\left[{ }^{\circ} \mathrm{C}\right]$ & 80.7 & 94.9 & 102.1 & 83.0 & 95.3 & 95.7 & 98.6 \\
$\dot{m}_{\text {wf }}[\mathrm{kg} / \mathrm{s}]$ & 0.057 & 0.046 & 0.068 & 0.065 & 0.082 & 0.071 & 0.086 \\
$P_{\mathrm{m}}[\mathrm{W}]$ & 737 & 382 & 1184 & 1394 & 1820 & 1269 & 1648 \\
$\omega[\mathrm{rpm}]$ & 2296 & 2295 & 2296 & 1771 & 1771 & 2660 & 2660 \\
$\eta_{\text {vol }}$ & 0.86 & 0.84 & 0.84 & 0.78 & 0.77 & 0.92 & 0.93 \\
$\eta_{\exp }$ & 0.59 & 0.43 & 0.66 & 0.69 & 0.68 & 0.63 & 0.66 \\
\hline
\end{tabular}

Concerning the expander efficiency, in Equation (2), the reference transformation is an adiabatic isentropic expansion (denominator). This hypothesis, universally adopted, in reality introduces a conceptual error: the ideal transformation could be considered (with good approximation) as adiabatic, but only until the start of the exhaust phase, which, during voiding, is closer to an isochoric transformation. Besides, as Table 2 shows, the considered scroll machine allows for high efficiency values, with an average equal to 0.62 .

The experimental intake pressure and temperature, as well as the intake temperature, are introduced respectively at the intake and exhaust boundary conditions, while the revolution speed of the pump shaft is imposed equal to the experimental value. The numerical results in terms of mass flow rate, mechanical power and exhaust temperature 
are compared to the corresponding experimental values, and the differences are reported in Figures 5 and 6.

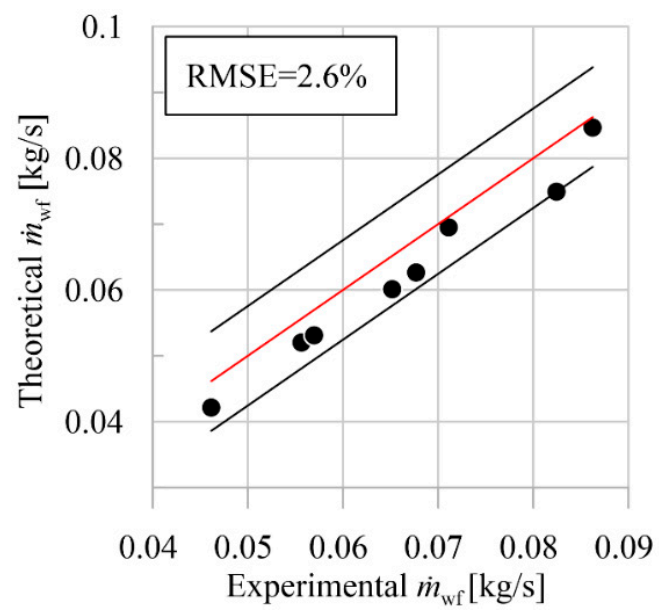

(a)

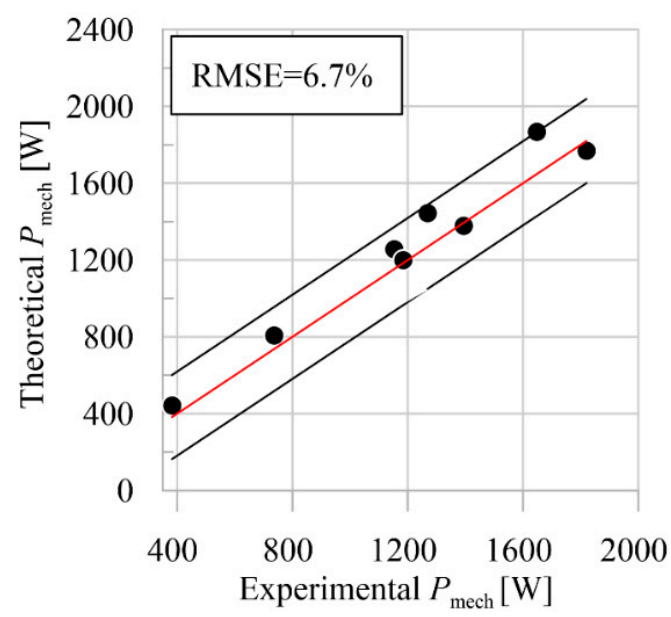

(b)

Figure 5. Comparison between experimental and theoretical mass flow rate (a) and mechanical power (b).

(a)

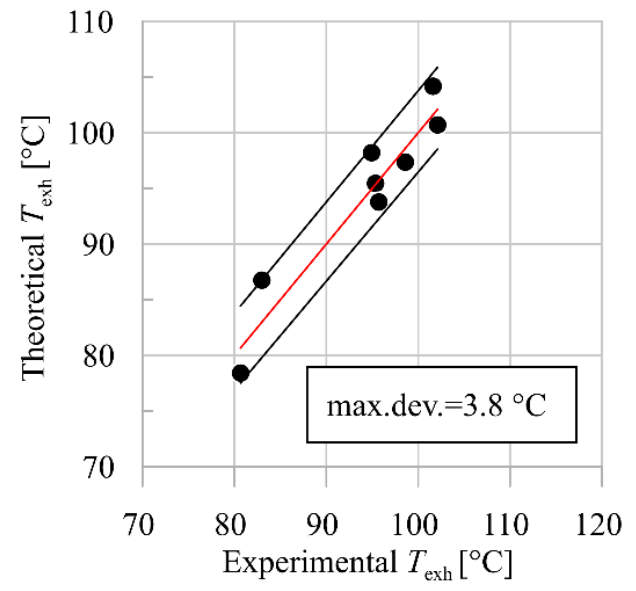

(b)

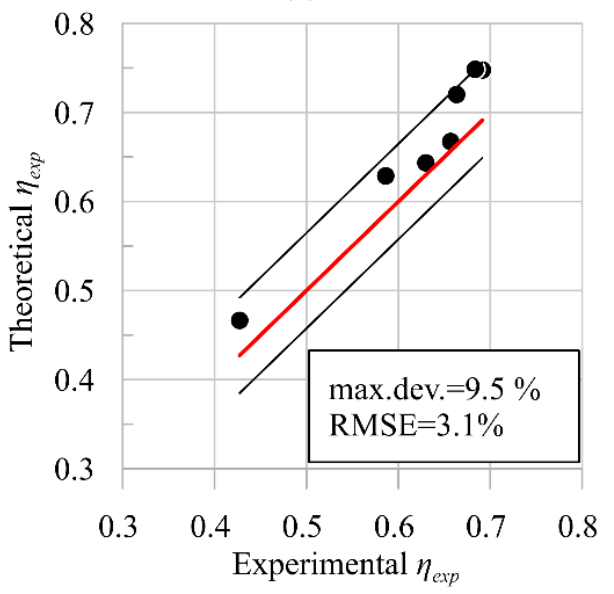

Figure 6. Comparison between experimental and theoretical exhaust temperature $T_{\text {exh }}(\mathbf{a})$ and expander efficiency $\eta_{\exp }(\mathbf{b})$.

The comparison between experimental and theoretical mass flow rate is shown in Figure 5a. It can be observed that there is a good agreement between experimental data and theoretical prediction, confirmed by the root mean square error RMSE being equal to $2.6 \%$. This means that the model is able to represent volumetric losses, i.e., the difference between the theoretical mass flow rate and the experimental one. This difference is due to the uncertainty associated with the leakages between adjacent vanes and between stator and rotor planes. A model closer to the real behavior for intake and exhaust phases would contribute to a more precise estimation: the knowledge of the pressure inside the vanes vs. rotation (indicated cycle) would be very useful additional information in the context of better understanding volumetric losses.

The model is also capable of representing the mechanical behavior of the machine, as confirmed by the low error between the experimental and theoretical mechanical power (Figure $5 b$ ). Indeed, the RMSE is equal to $6.7 \%$, showing that the mechanical subroutine of the model ensures a consideration of the power lost due to friction. 
The satisfactory robustness of the model is confirmed when considering two further validation quantities: the exhaust temperature and the indicated cycle (Figures 6 and 7).

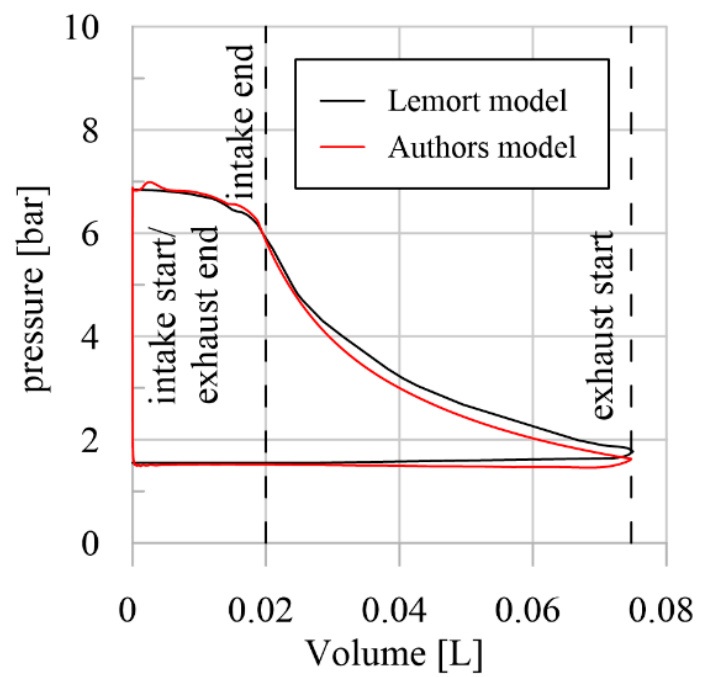

Figure 7. Comparison between indicated $\mathrm{p}-\mathrm{V}$ cycles predicted by the authors' model and the one developed by Lemort in [35].

In Figure 6a, the comparison between experimental and theoretical exhaust temperatures is reported, showing low absolute errors (the maximum absolute deviation is equal to $3.8^{\circ} \mathrm{C}$ ). Therefore, the model appears to be able to reproduce the expansion phase taking place inside the machine, as the temperature of the working fluid predicted by the model is close to that observed experimentally when the exhaust port opens.

Confirmation of the model's capability to accurately predict the whole expander behavior can be seen in Figure 6b, where the experimental expander efficiency data is compared with the model predictions. The results show a good agreement between the experiments and predictions, with a maximum deviation of $9.5 \%$ and an RMSE of 3.1\%. This is a satisfying result considering that the maximum deviation of global efficiency is also affected by errors present in mass flow rate predictions (the volumetric behavior of the expander) and in the mechanical power produced (mechanical behavior).

The validation allowed for the identification of quantities which are very difficultly to know; these quantities are reported in Table 3. By definition, these values allow for the minimization of differences between the measured and predicted values. Note that the tip radial leakage area was set as an input element, being directly summed to the inlet port area during the ending phase of the suction process. Clearance gaps affect the volumetric losses, which also represent an energetic loss. Indeed, the working fluid which by-passes the chambers flowing directly to the exhaust port or to adjacent chambers reduces the power produced by the machine. Thus, there is only one set of clearance gaps which, at the same time, allows for the minimization of errors in terms of mass flow rate and scroll power (Table 3). This means that the clearance gaps are univocally defined during the validation phase, thus enhancing the model's reliability.

Table 3. Model calibration coefficients.

\begin{tabular}{ccc}
\hline Parameter & Value & Unit of Measurement \\
\hline Flank leakage gap & 46 & $\mu \mathrm{m}$ \\
Flank leakage length & 25 & $\mathrm{~mm}$ \\
Tip radial leakage area & 7 & $\mathrm{~mm}^{2}$ \\
Friction torque $F_{\mathrm{T}}$ & 2.5 & $\mathrm{Nm}$ \\
\hline
\end{tabular}


It is worth to notice that, in the evaluation of mechanical power, friction power loss is defined following an empirical approach which involves tuning the friction torque based on the experimental results in accordance with common approaches found in the literature [35,37]. In fact, as reported in the previous section, the complex scroll geometry and relative contact of multiple parts make complex the development of an analytical friction model.

A better matching of the theoretical predictions with the experimental data would be able to be reached if the indicated cycle was measured; this would have allowed the estimation of the mechanical efficiency by decoupling mechanical and indicated power.

Nevertheless, this measurement is not possible for scroll expanders due their complex geometrical configurations. In fact, to the authors' best knowledge, there is a lack of experimental assessment of scroll expander indicated cycles in the literature. This reinforces the importance of the indicated cycle prediction made by the model, because it could give an indication of the intimate behavior of the fluid inside the machine and a representation of the filling and emptying of the vanes. With the aim of observing these fluid-dynamic aspects, the indicated cycle predicted by the model is reported in Figure 7. The indicated cycle provided by Lemort's model is also shown in the same Figure [35]. It is interesting to observe that both models indicate the same trend in the intake phase, allowing for observations in pressure reduction during the last part of this phase. The two models also converge in the reproduction of the expansion phase, presenting only a slight difference in the last part of it, while the exhaust process is quite coincident. Therefore, the model prediction allows for the enhancement of knowledge relating to scroll fluid-dynamic behavior, opening a way towards new frontiers of scroll expander optimization.

\section{Results}

\subsection{Feasibility Assessment of a DIP Technology for the Scroll Expander}

The DIP technology is a novel design solution for positive displacement expanders consisting of the introduction of a further intake port after the main one. The second intake port is in an angular position corresponding to the expansion phase of the machine, positioned just after the first one. In this way, the machine can elaborate a higher mass flow rate without producing an increase of the expander inlet pressure, and in the process keeps the pressure ratio across the expander constant. This produces an enhancement of the indicated power of the machine, as can be observed in Figure 8, where the indicated cycle of an original manufacturer machine (SIP) and of a DIP machine is reported. It has been calculated thanks to the model previously validated. In the DIP machine, the suction produced by the second port starts immediately at the end of the main one, thus the decrease in pressure due to the expansion is prevented by the extra mass flow rate entering the machine through the additional intake port.

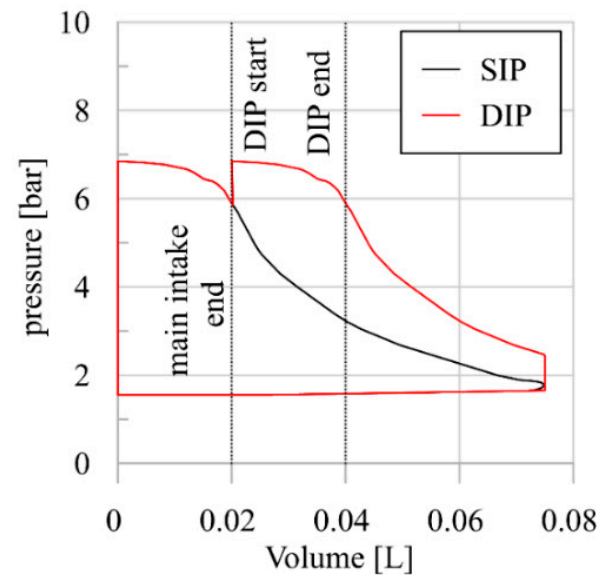

Figure 8. Dual-intake-port technology concept [31] 
This provides an increase in the indicated power and consequently of the mechanical power provided by the machine. In other words, the DIP technology increases the permeability of the machine $\alpha$ expressed as the ratio between the mass flow rate elaborated by the expander and the pressure ratio at the intake and the exhaust side of the machine $\Delta p_{\exp }$ (Equation (3)):

$$
\alpha=\frac{\dot{m}_{\mathrm{wf}}}{\Delta p_{\exp }}
$$

The extra mass flow rate entering the machine leads to an enhancement of the mechanical power produced by the expander, enhancing the energy recovery of the unit and avoiding an increase in inlet pressure which would be produced by an extra working fluid mass flow rate (when compared to the designed one). It is also evident how the fluid entering through the second port increases the pressure at the opening of the discharge port, producing an isochoric expansion which represents a loss with respect to an eventual residual adiabatic expansion.

The capability to aspirate a greater mass flow rate allows for a greater thermal energy recovery from the exhaust gases and could be suitable when the ICE works at full load. This means that the HRVG would be able to operate in off design conditions, enabling a greater working fluid flow rate. Nevertheless, in a conventional expander, the intake expander pressure grows quite linearly with the mass flow rate [32], which means that a high increase of it could lead to an excessive intake pressure value, compromising the integrity and operability of the machine's components (e.g., sealing systems). Therefore, the DIP technology allows for an increase in $\alpha$, thereby maintaining the intake pressure and allowing for a significant increase in the working fluid mass flow rate.

The feasibility of DIP technology has been widely assessed by the authors in the context of sliding rotary vane expanders, where an increase of $40-50 \%$ of the expander power was observed with respect to the SIP version [31]. DIP technology is expected to be similarly beneficial from a conceptual point of view when it comes to scroll expanders, as they are positive displacement devices. Nevertheless, due to their more complex geometry, the introduction of a DIP technology is less straightforward in this context than in the case of SVREs. In fact, in SVREs it is sufficient to introduce a further port on the stator (after the main intake port), while for scroll expanders, two symmetric orifices are needed (Figure 9). This is because, during the operation, the scroll intake chamber $(1 \mathrm{a}+1 \mathrm{~b}$ in Figure 9) branches off in two parts ( $2 a$ and $2 b$ ); therefore, to feed them during the dual intake phase, two additional ports are needed (blue orifices in Figure 9, which simultaneously feed the scroll chambers $3 a$ and $3 b$ ).

In this way, the two orifices (which behave like a second intake port) allow for the a and b chambers (Figure 9) to be synchronously fed, thus preventing imbalances between the mass flow rates of the two intake branches during the cycle.

Moreover, despite this consideration of the DIP position, this technology could be easily implemented also for the scroll, as the orifices can be placed on the front casing of the machine, which in general presents a quite flat surface. Another aspect to consider is that the orifice should have a diameter which avoids the communication channel between adjacent chambers ( $3 a$ and $3 b$ in Figure 9). This situation should be avoided because it breaks the symmetry of the intake phase; thus, the diameter of the second port realized by means of two orifices cannot exceed the thickness of the orbiting and fixed spirals.

Considering all these aspects, a DIP scroll machine was designed for the test case (with orifice diameters equal to spiral thickness, $2.25 \mathrm{~mm}$ ). Several positions of the orifices were considered and their effects on the scroll machine were evaluated thanks to the proposed previously validated theoretical model. 


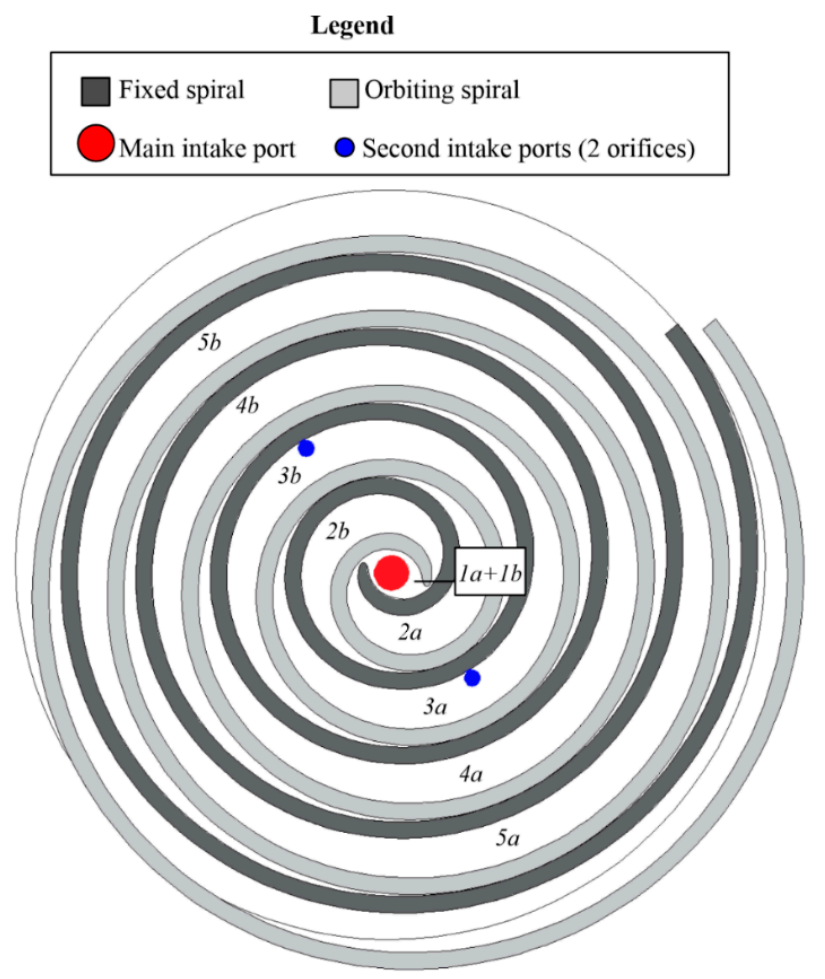

Figure 9. Position of the main and of the second intake DIP ports and definition of the scroll chambers by the interaction of orbiting and fixed spirals.

To find the best position for the orifices, five cases were considered, which involved varying their angular positions while always keeping their diameters constant $(2.25 \mathrm{~mm})$. The position of the orifices is expressed as the function of the angular delay $\varphi$ with respect to the main intake port: in the considered cases, $\varphi$ is equal to $360^{\circ}$ (Figure 10a), $540^{\circ}$ (Figure 10b), $720^{\circ}$ (Figure 10c), $900^{\circ}$ (Figure 10d) and $1080^{\circ}$ (Figure 10e), respectively. Thus, the angular delay $\varphi$ expresses the angular rotations which the orbiting spiral of the scroll should perform to feed two symmetric chambers through the second intake ports.

For instance, considering Figure 10a, where $\varphi=360^{\circ}$, a complete rotation should be completed by the scroll orbiting spiral prior to the chamber $(1 a+1 b)$ branching off into two symmetric chambers, which are simultaneously filled through the second intake ports. The higher is $\varphi$, the larger the angular distance between the main and the second intake phases. It is worth to noticing that, for the convention adopted, a reference of the angular rotation is taken at the start of the main intake phase. For all the cases, expander intake and exhaust pressures are equal to 7 bar and 1.4 bar, respectively, while the expander intake temperature is equal to $145.6^{\circ} \mathrm{C}$. The working fluid considered is always R123.

The performance of the scroll with a DIP technology was compared to that of the SIP case and the results are reported in Table 4 and Figure 11 in terms of indicated cycles.

Table 4. Comparison between the SIP and DIP scroll performance.

\begin{tabular}{ccccccc}
\hline Case & SIP & $\boldsymbol{\varphi = ~} \mathbf{3 6 0}^{\circ}$ & $\boldsymbol{\varphi = \mathbf { 5 4 0 } ^ { \circ }}$ & $\boldsymbol{\varphi = \mathbf { 7 2 0 } ^ { \circ }}$ & $\boldsymbol{\varphi = \mathbf { 9 0 0 } ^ { \circ }}$ & $\boldsymbol{\varphi = \mathbf { 1 0 8 0 } ^ { \circ }}$ \\
\hline$\dot{m}_{\mathrm{wf}}[\mathrm{kg} / \mathrm{s}]$ & 0.059 & 0.071 & 0.081 & 0.085 & 0.087 & 0.089 \\
$P_{\text {mech }}[\mathrm{W}]$ & 1131 & 1352 & 1410 & 1333 & 1216 & 1098 \\
$\eta_{\exp }[\%]$ & 58.3 & 57.9 & 52.9 & 47.4 & 42.3 & 37.4 \\
$\Delta \dot{m}_{\mathrm{wf}}[\%]$ & 0.0 & 20 & 37 & 45 & 48 & 51 \\
$\Delta P_{\text {mech }}[\%]$ & 0.0 & 19.5 & 25 & 18 & 7.4 & -2.9 \\
$\Delta \eta_{\exp }[\%]$ & 0.0 & -0.7 & -9.2 & -18.7 & -27.4 & -35.8 \\
\hline
\end{tabular}




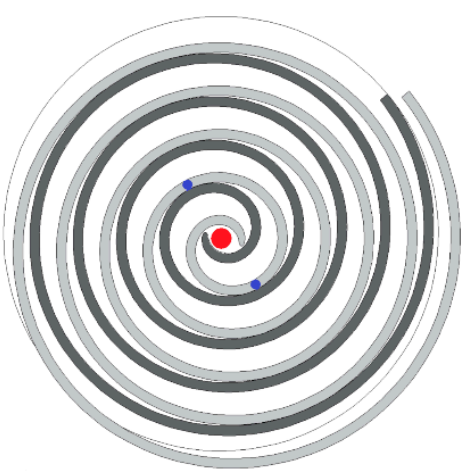

(a) $\varphi=360^{\circ}$

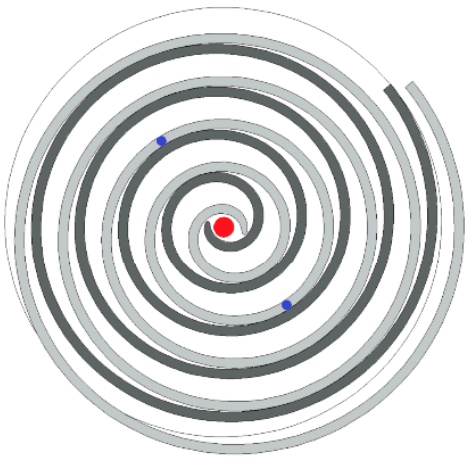

(c) $\varphi=720^{\circ}$

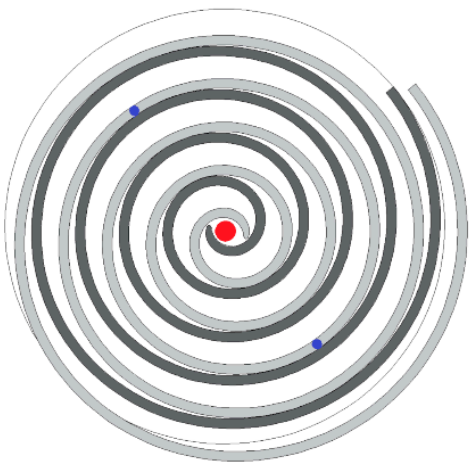

(e) $\varphi=1080^{\circ}$

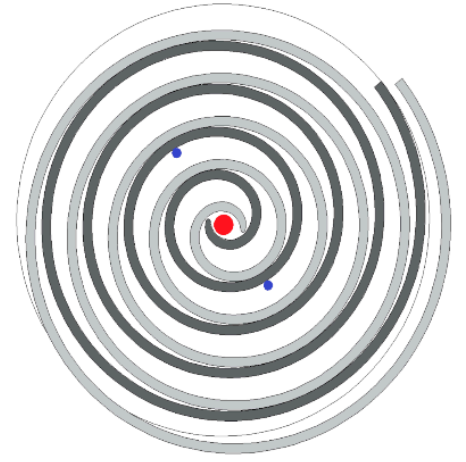

(b) $\varphi=540^{\circ}$

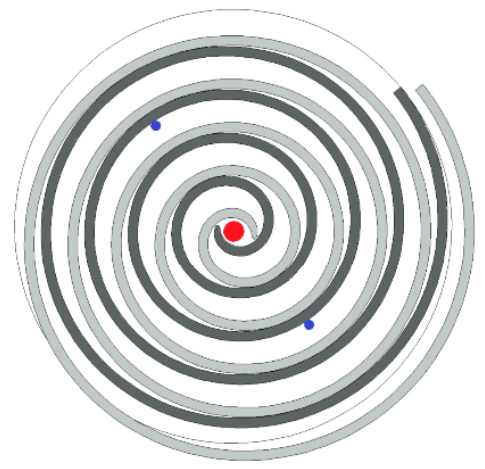

(d) $\varphi=900^{\circ}$

Figure 10. Position of second intake ports as the function of angular delay $\varphi$ with respect to the main intake port: $\varphi=360^{\circ}$ (a), $\varphi=540^{\circ}$ (b), $\varphi=720^{\circ}$ (c), $\varphi=900^{\circ}$ (d) and $\varphi=1080^{\circ}(\mathbf{e})$.

The results show that the higher the $\varphi$ (and hence the distance between the opening of the second port and the closure of the main one), the larger the increase of working fluid mass flow rate aspirated. Indeed, the mass flow rate increases from $0.059 \mathrm{~kg} / \mathrm{s}$ of the SIP to $0.089 \mathrm{~kg} / \mathrm{s}$ in the case with $\varphi=1080^{\circ}$ (Figure 11e): in this case, the maximum angular distance between the main intake port and second one is observed. An increase in machine permeability is evident, with the growth of mass flow rate equal to almost $50 \%$ for the same in/out scroll pressure difference. Nevertheless, considering the produced mechanical power, it does not increase continuously with the increase in mass flow rate. Indeed, $P_{\text {mech }}$ grows until the case with $\varphi=540^{\circ}$ (Figure 11b), in which the mechanical power increase $\Delta P_{\text {mech }}$ (with respect the SIP) reaches $25 \%$. After this best power case in terms of larger $\varphi$ values, $P_{\text {mech }}$ decreases until it is lower $(2.9 \%)$ than the value for the SIP technology (Figure 11e). 

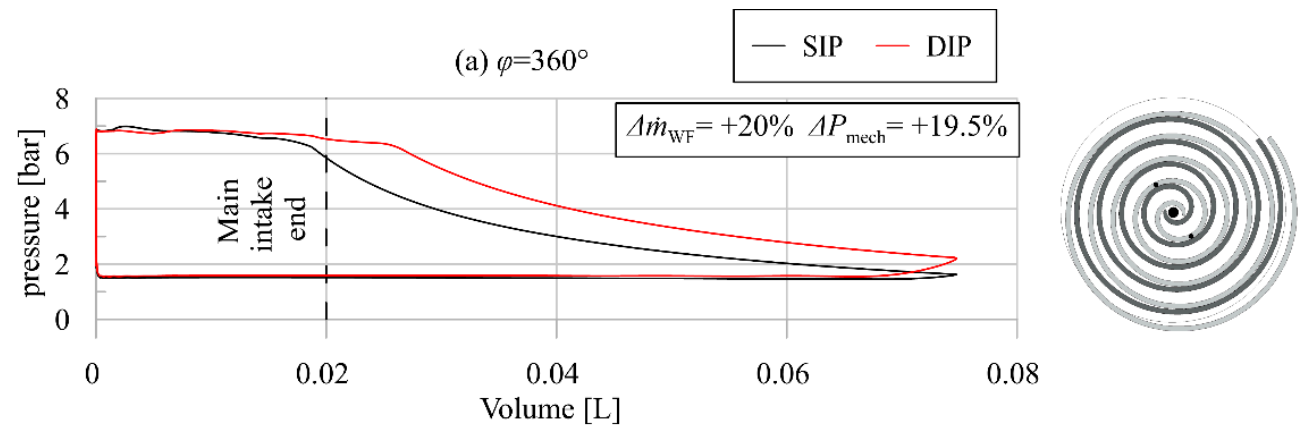

(b) $\varphi=540^{\circ}$
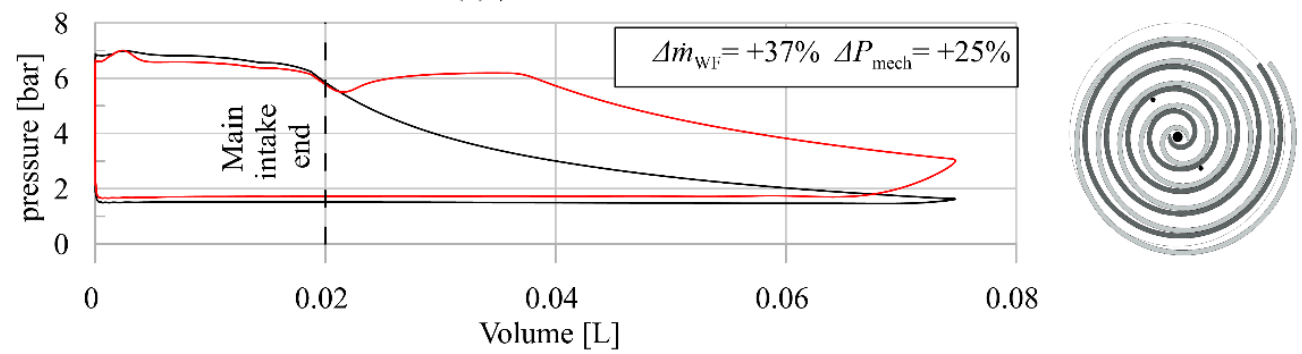

(c) $\varphi=720^{\circ}$
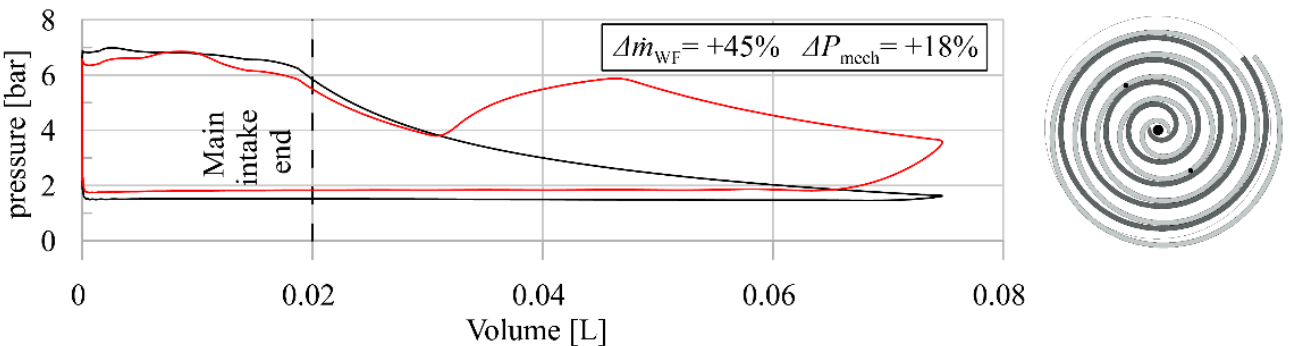

(d) $\varphi=900^{\circ}$
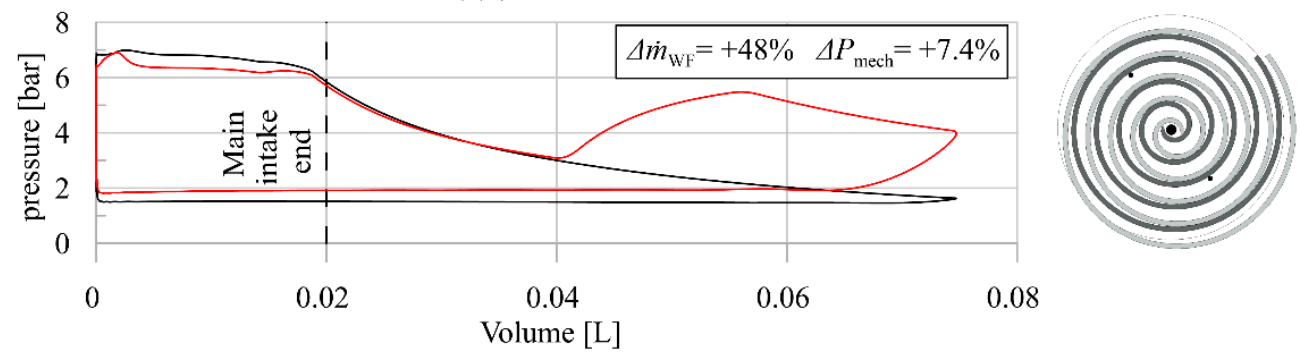

(e) $\varphi=1080^{\circ}$
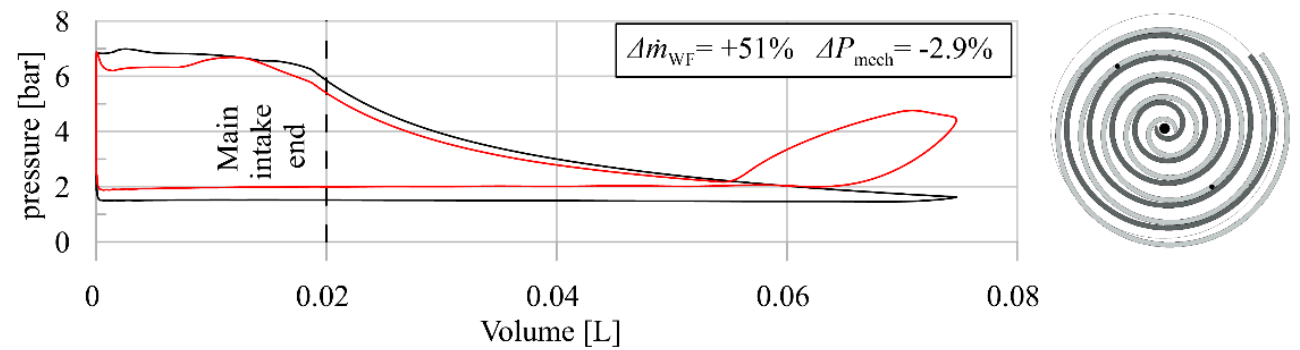

Figure 11. Comparison between the SIP and DIP scroll indicated cycles when $\varphi=360^{\circ}(\mathbf{a}), \varphi=540^{\circ}$ (b), $\varphi=720^{\circ}(\mathbf{c}), \varphi=900^{\circ}(\mathbf{d})$ and $\varphi=1080^{\circ}(\mathbf{e})$.

This means that the second intake port should not be placed beyond a given volume increase when the pressure inside the chamber is too low. In this situation, the further mass flow rate entering the vane does not produce a sensible increase of the chamber pressure, as can be observed in the indicated $\mathrm{p}-\mathrm{V}$ diagrams reported in Figure 11. Therefore, this 
further mass flow rate is useless, as it does not produce a benefit on indicated power. For this reason, the best position for the second port is in correspondence with the middle of the expansion phase, where the best effect on the indicated diagram growth is observed (Figure 11b).

Considering the expander global efficiency, in all cases the DIP technology presents a lower efficiency with respect the SIP technology, as it can be observed from Figure 12a, where $\Delta \eta_{\exp }$ is reported.

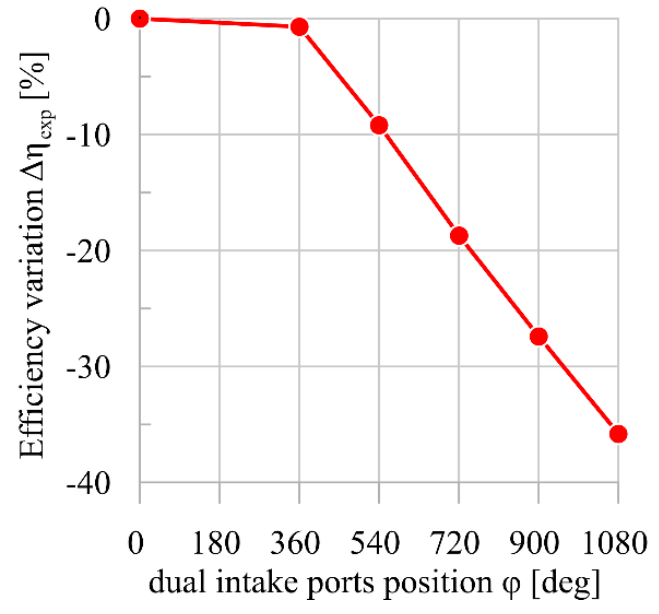

(a)

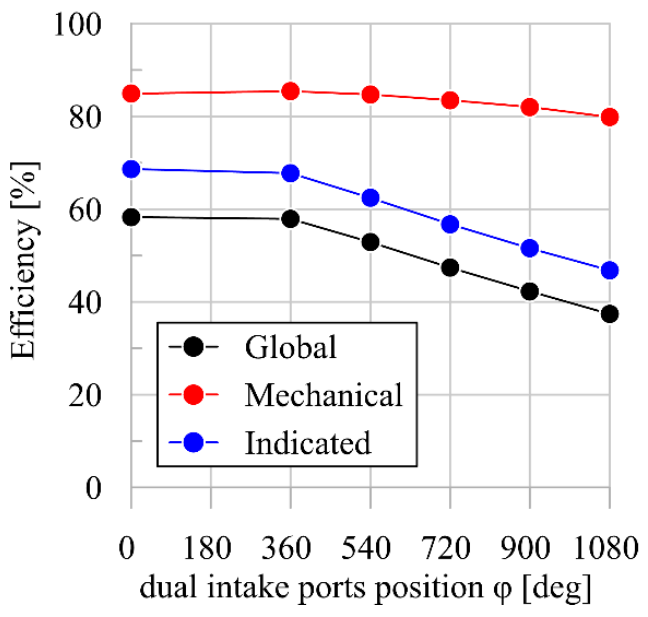

(b)

Figure 12. Efficiency variation $\Delta \eta_{\exp }$ (a) and global, mechanical and indicated efficiencies as function of dual intake ports' position (b) of the scroll expander.

From Figure $12 \mathrm{a}$, it can be seen that after $\varphi=360^{\circ}$ (where the DIP and SIP technologies have nearly the same efficiency $\left(\Delta \eta_{\text {exp }}=0\right)$ ) a linear decrease is observed.

To understand the reason behind such behavior, it is useful to consider the expander efficiency chain, which can be obtained as follows.

In Equation (2), the global efficiency was expressed as the ratio between the mechanical power and the power produced by the expander in case of an adiabatic iso-entropic transformation and in the absence of volumetric losses (leakages). In reality, the global efficiency can be expressed as in Equation (4), which outlines the role of volumetric, indicated and mechanical efficiencies:

$$
\eta_{\text {exp }}=\frac{P_{\mathrm{m}}}{\dot{m}_{\mathrm{wf}}\left(h_{\mathrm{in}}-h_{\mathrm{out}, \text { is }}\right)}=\frac{\dot{m}_{\mathrm{vane}}}{\dot{m}_{\mathrm{wf}}} \cdot \frac{P_{\mathrm{ind}}}{\dot{m}_{\mathrm{vane}}\left(h_{\mathrm{in}}-h_{\mathrm{out}, \text { is }}\right)} \cdot \frac{P_{\mathrm{m}}}{P_{\mathrm{ind}}}=\eta_{\mathrm{vol}} \cdot \eta_{\text {ind }} \cdot \eta_{\mathrm{mech}}
$$

Being:

$$
\dot{m}_{\mathrm{vane}}=\dot{m}_{\mathrm{wf}}-\dot{m}_{\text {leak }}
$$

The DIP technology modifies all of these three efficiencies, and for a direct comparison with the conventional machine (SIP) it is important to fix the conditions of this comparison. In this case, two situations are possible: either the two machines (a) have the same intake pressure, or (b) are crossed by the same mass flow rate.

In case (a), DIP technology leads to an improvement of volumetric efficiency, with $\dot{m}_{\text {vane }}$ being increased and $\dot{m}_{\text {leak }}$ being comparable with the value in the case of SIP technology. The increase of $\dot{m}_{\text {vane }}$ causes a more pronounced isochoric expansion when the exhaust port opens, so the indicated efficiency decreases (Figure 12b). This is because the remaining adiabatic isentropic expansion becomes significant until the discharge pressure. Moreover, the mechanical efficiency sees two opposite effects when DIP technology is considered: an increase in indicated power, but also an increase in friction. The overall effect therefore depends on the balance of these two contributions. The overall effect is demonstrated in Figure $12 b$. 
In case (b), the DIP expander is characterized by a lower intake pressure when compared to the SIP. This has a positive impact on volumetric efficiency, being the pressure difference the main driver of the volumetric losses which decrease. Concerning the indicated efficiency, even though the angular position of the second port is properly designed, the benefit among different contributions regarding its definition is not guaranteed. On the contrary, the mechanical efficiency of DIP technology increases because the friction losses diminish, meaning that the average mean pressure is lower. In most cases, the net effect is an increase in the global efficiency when compared to the SIP technology.

In addition the impact of the DIP on expander performance, it is also important to observe the benefits introduced by such technology in terms of plant efficiency.

In fact, the use of the DIP technology provides an increase of the whole ORC-based plant efficiency if the position of the second port is optimized. The comparison should be carried out considering the same working fluid flow rate entering the expander, a condition which means that a fixed thermal power from the hot source is recovered. For a flow rate equal to $0.071 \mathrm{~kg} / \mathrm{s}$, the SIP expander operates at $7.9 \mathrm{bar}$ with a pressure drop inside the machine equal to 6.1 bar (see Table 2), while the DIP expander operates at 7.0 bar with a pressure drop equal to $5.6 \mathrm{bar}$ (see Table 4). The power produced in the first case is $1269 \mathrm{~W}$ and $1352 \mathrm{~W}$ in the second case. Considering that the power absorbed by the pump is lower in the DIP case, the plant efficiency is therefore greater when a double intake port is considered.

\subsection{Comparison with DIP Technology for Sliding Rotary Vane Expander SVRE}

It has been already observed that volumetric expanders have intrinsic advantages with respect to dynamic machines for small size ORC-based power units. A comparison between scroll and sliding vane rotary expanders is more complex and does not lead to a clear and definitive conclusion. In the following, the two machines were compared in terms of performance due to the adoption of a DIP technology.

The DIP technology was originally conceived to be applied to sliding rotary vane expander [31]. As reported by the authors in their previous works [31,32], the benefits introduced by such novel technology to SVREs are multiple and noteworthy, since DIP technology allows for the improved performance of the expander performance in many respects. Firstly, the dual intake technology ensures that the operability of the machine can be widened. Indeed, the introduction of a further suction port makes the expander more permeable in such a way it can increase the mass flow rate for a given pressure difference between expander intake and exhaust sides. Consequently, the dual intake (or supercharged) expander produces a higher mechanical power, thus increasing the energy recovery. These benefits were also observed in terms of the SVRE design. As matter of fact, the adoption of DIP technology opens the way to expander downsizing with respect to the case of the single port. This is made possible by another aspect of permeability growth, which can be observed when a comparison with the SIP expander is conducted while keeping the mass flow rate constant. In this case, the DIP expander, being more permeable, presents a lower intake pressure with a slight reduction in the power produced. Nevertheless, by reducing the dimensionsof the DIP expander, the intake pressure grows, producing a comparable power more efficiently. In fact, if the dimensions of the expander diminish, the power loss due to friction decreases too, as the mass of the elements in relative motion are lower. Considering these important benefits, confirmed both experimentally and numerically [31,32], the DIP SVRE was considered as a reference for the evaluation of the suitability of that novel technology. Therefore, the performance of the DIP Scroll was compared to that of the DIP SVRE to analyze similarities and differences in the behavior of the two supercharged machines.

For this reason, a single intake port (SIP) SVRE was designed to operate in the same conditions in which the scroll expander were analyzed. The conditions were: $\dot{m}_{\mathrm{wf}}=0.059 \mathrm{~kg} / \mathrm{s}$, $p_{\text {exp,in }}=7$ bar and $p_{\text {exp,out }}=1.4$ bar (first column of Table 4 ). This was done thanks to the experimentally validated numerical model developed in [31]. The main dimensions of the 
SVRE are reported in Table 5. In this design, a further intake port was introduced with different angular positions, defined by the angle $\varphi$ due to the difference between the end of the main intake port and the start of the dual intake port (Figure 13). Therefore, the performances of the SVRE were calculated when the DIP technology is considered and compared to those of the scroll expander previously discussed.

Table 5. SVRE expander geometry and intake and exhaust ports.

\begin{tabular}{ccc}
\hline Description & Value & Unit of Measurement \\
\hline Stator diameter & 75.9 & {$[\mathrm{~mm}]$} \\
Rotor diameter & 65 & {$[\mathrm{~mm}]$} \\
Eccentricity & 5.45 & {$[\mathrm{~mm}]$} \\
Expander width & 60 & {$[\mathrm{~mm}]$} \\
Blade thickness & 3.96 & {$[\mathrm{~mm}]$} \\
Blade length & 17 & {$[\mathrm{~mm}]$} \\
Intake port opening angle & 4.4 & {$[\mathrm{deg}]$} \\
Intake port closing angle & 48 & {$[\mathrm{deg}]$} \\
Exhaust port opening angle & 180 & {$[\mathrm{deg}]$} \\
Exhaust port closing angle & 322 & {$[\mathrm{deg}]$} \\
Angular extent of the auxiliar intake port & 10.6 & {$[\mathrm{deg}]$} \\
Rated revolution speed & 1500 & {$[\mathrm{RPM}]$} \\
\hline
\end{tabular}

Five positions were considered for the auxiliary (or dual intake) port: $\varphi=43.2^{\circ} ; \varphi=53.2^{\circ} ; \varphi=63.2^{\circ} ; \varphi=73.2^{\circ}$, $\varphi=83.2^{\circ}$.

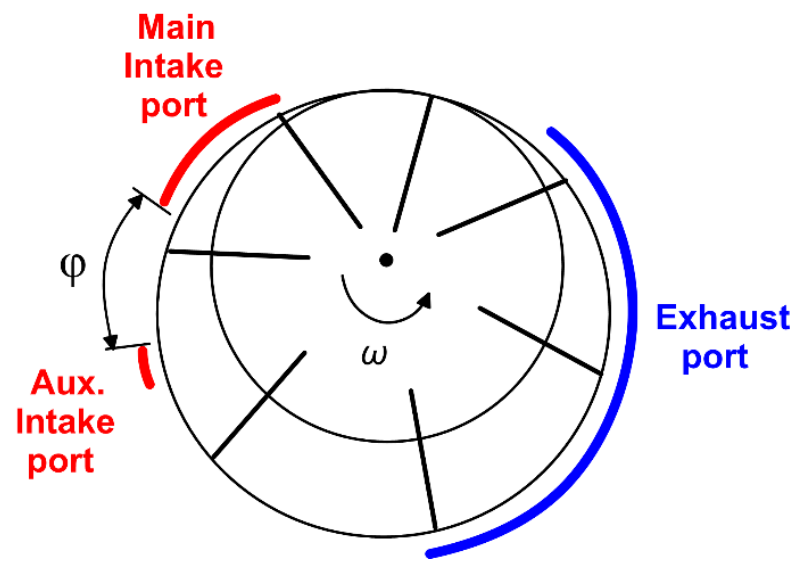

Figure 13. DIP SVRE expander.

Higher angular delays in dual intake port opening were not taken into consideration, because in this case the dual intake phase shares an angular interval with the discharge phase, causing a critical volumetric loss directly from the intake to the exhaust [31]. In Table 6, the performance of the SIP SVRE is reported together with that of the DIP by varying the angular position of the auxiliary port.

Table 6. Comparison between the SIP and DIP SVRE performance.

\begin{tabular}{ccccccc}
\hline Case & SIP & $\boldsymbol{\varphi = 4 3 . 2 ^ { \circ }}$ & $\boldsymbol{\varphi = 5 3 . 2 ^ { \circ }}$ & $\boldsymbol{\varphi = 6 3 . 2 ^ { \circ }}$ & $\boldsymbol{\varphi = 7 3 . 2 ^ { \circ }}$ & $\boldsymbol{\varphi = 8 3 . 2 ^ { \circ }}$ \\
\hline$\dot{m}_{\mathrm{wf}}[\mathrm{kg} / \mathrm{s}]$ & 0.06 & 0.11 & 0.12 & 0.12 & 0.13 & 0.14 \\
$P_{\text {mech }}[\mathrm{W}]$ & 816 & 1491 & 1496 & 1489 & 1471 & 1392 \\
$\eta_{\exp }[\%]$ & 43 & 40 & 39 & 37 & 35 & 30 \\
$\Delta \dot{m}_{\mathrm{wf}}[\%]$ & 0.0 & 95.2 & 104.9 & 114.0 & 120.4 & 143.2 \\
$\Delta P_{\text {mech }}[\%]$ & 0.0 & 82.7 & 83.3 & 82.5 & 80.2 & 70.6 \\
$\Delta \eta_{\exp }[\%]$ & 0.0 & -6.4 & -10.5 & -14.7 & -18.2 & -29.9 \\
\hline
\end{tabular}


As Tables 4 and 6 show, despite the SIP SVRE elaborating an equal mass flow rate for the same pressure difference when compared to the SIP Scroll, the power produced by the SVRE is lower. Indeed, in the case of the SVRE, the power is $816 \mathrm{~W}$, while for the scroll machine it is $1131 \mathrm{~W}$. This is due to the lower global expander efficiency of the SVRE (43\%) in comparison to the Scroll (58.3\%).

Nevertheless, the introduction of DIP on vane expander leads to a boosting of the mass flow rate elaborated by the machine and consequently of the mechanical power produced. The mass flow rate and power gains are higher than those achieved by the DIP Scroll. In fact, in the case of the SVRE, the increase of mass flow rate varies from $95 \%$ to $143.2 \%$ when $\varphi$ grows from $43.2^{\circ}$ to $83.2^{\circ}$. However, similar to what happens in a DIP Scroll expander, the power increase does not follow the flow rate gain but assumes a maximum in correspondence of $53.2^{\circ}$ and then decreases until $70 \%$ when $\varphi$ is equal to $83.2^{\circ}$.

The reason of this behavior can be observed from the indicated cycle of the DIP SVRE reported in Figure 14. The analysis of the indicated cycle shows that the higher the delay of the dual intake phase, the larger the volume of the chamber when the further mass flow rate enters the expander. Therefore, the extra mass flow rate produces a lower boost effect on chamber pressure, as the density grows less than in the case of the DIP when the chamber presents a lower volume (in the first stage of the expansion phase). These results are in accordance with those reported in [31], obtained using a different fluid.

The analysis of the indicated cycle of the DIP SVRE also explains the motivation behind the higher impact of the DIP on the SVRE in terms of power in comparison with the DIP scroll. In fact, the DIP technology in the SVRE produces a greater isobaric trend in terms of extended volume of the indicated cycle in correspondence with the dual intake port (Figure 14) when compared to the scroll machine. The reason behind this is related to the architecture of the two devices.

Indeed, in the SVRE machine, one cycle (intake, expansion and exhaust) is completed within one shaft revolution, whereas the scroll machine needs more shaft revolutions (five in this case) to perform a complete cycle. This means that DIP technology in the SVRE is concentrated in a lower angular interval and, consequently, the extra mass flow rate produces greater benefits on pressure boost and, thus, on power gain.

On the other hand, DIP technology in the SVRE produces a greater decrease in expander efficiency (with respect the SIP version) than in the case of the DIP Scroll. Indeed, as it can be seen in Figure 15a, the DIP SVRE efficiency decreases from $43 \%$ to $30 \%$ when the $\varphi$ rises from $43.2^{\circ}$ to $83.2^{\circ}$, whereas the DIP Scroll exhibits a reduction from $60 \%$ to $40 \%$. This difference is mainly due by two causes:

1. The first of these is the higher efficiency of the SIP Scroll $(60 \%)$ when compared to the SVRE $(43 \%)$.

2. The second is that in the SVRE, the isochoric expansion at the end of the auxiliary intake phase is higher than in the case of the DIP Scroll. This is the effect of the higher extra mass flow rate on indicated power in the SVRE.

Nevertheless, for the angular position in which the DIP reaches the best performance (43.2-53. $2^{\circ}$ for SVRE and $0-540^{\circ}$ for Scroll) the efficiency is almost the same as the SIP machines. Indeed, the efficiency reduction of the two machines assumes a maximum value of $10-12 \%$ (Figure 15b). Moreover, this low efficiency reduction is a reasonable price to pay considering the operability gain obtained with the DIP, which leads to a higher recovery efficiency of the unit. 


$$
- \text { SIP }- \text { DIP }
$$

(a) $\varphi=43.2^{\circ}$

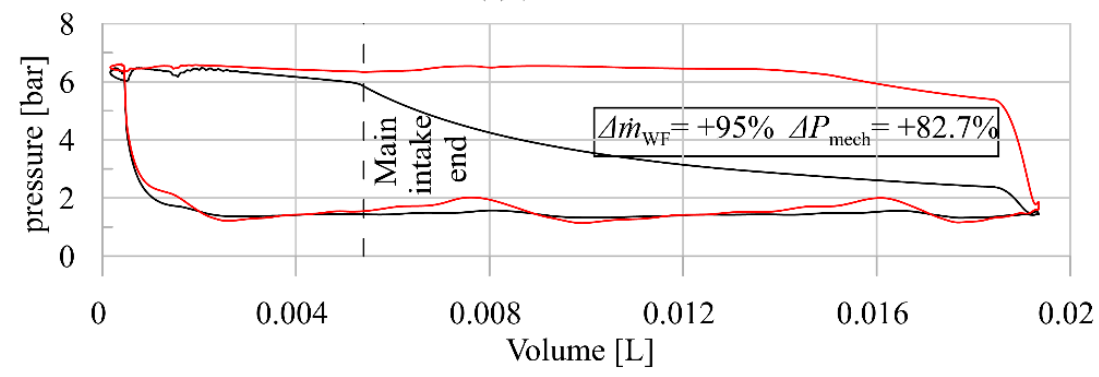

(b) $\varphi=53.2^{\circ}$

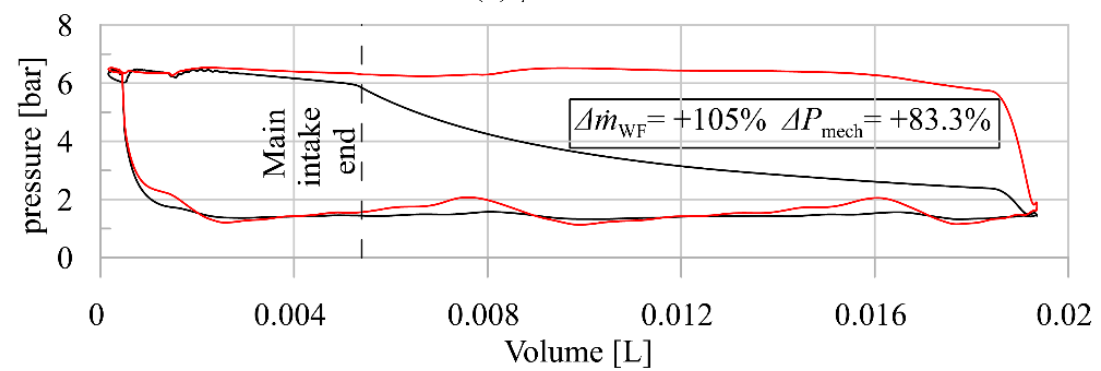

(c) $\varphi=63.2^{\circ}$

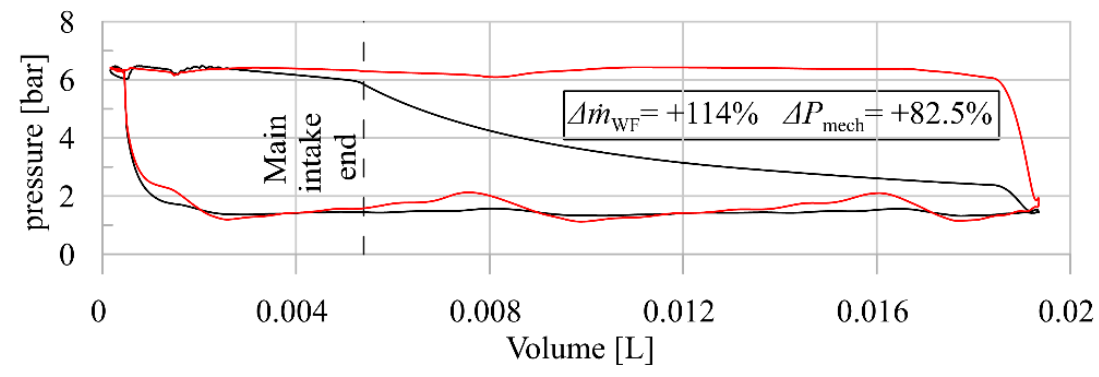

(d) $\varphi=73.2^{\circ}$

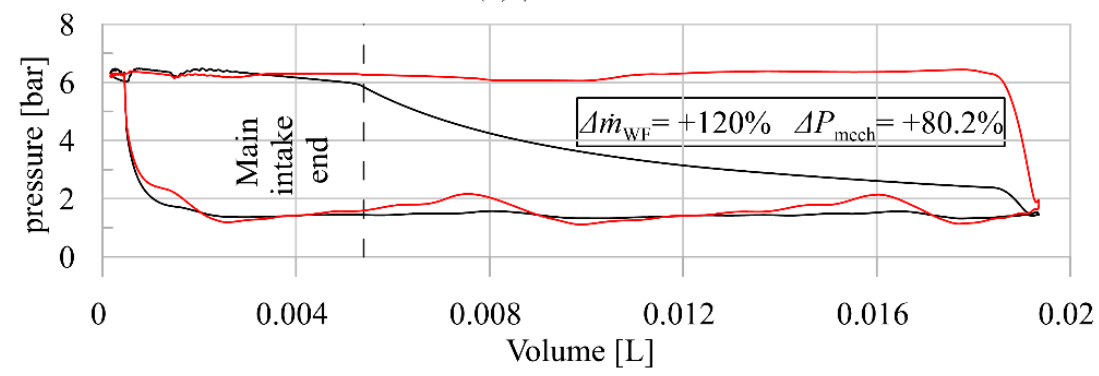

(e) $\varphi=83.2^{\circ}$

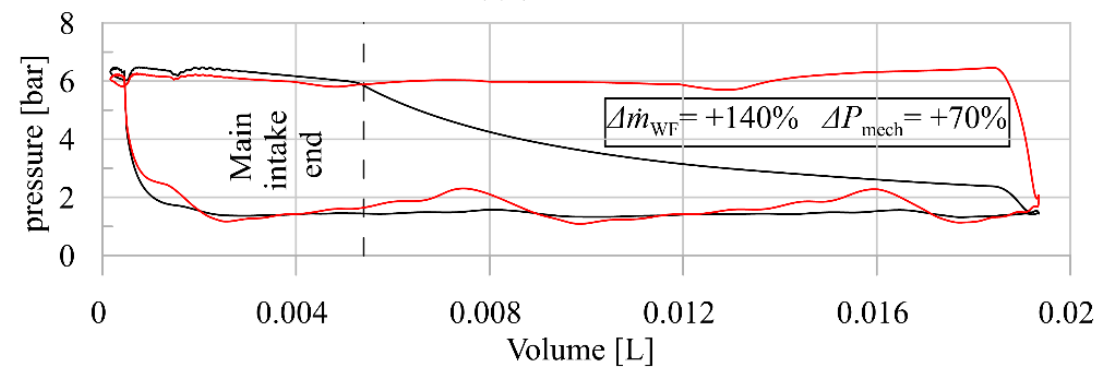

Figure 14. Comparison between the SIP and DIP SVRE indicated cycles when $\varphi=43.2^{\circ}(\mathbf{a}), \varphi=53.2^{\circ}$ (b), $\varphi=63.2^{\circ}(\mathbf{c}), \varphi=73.2^{\circ}(\mathrm{d})$ and $\varphi=83.2^{\circ}(\mathbf{e})$. 


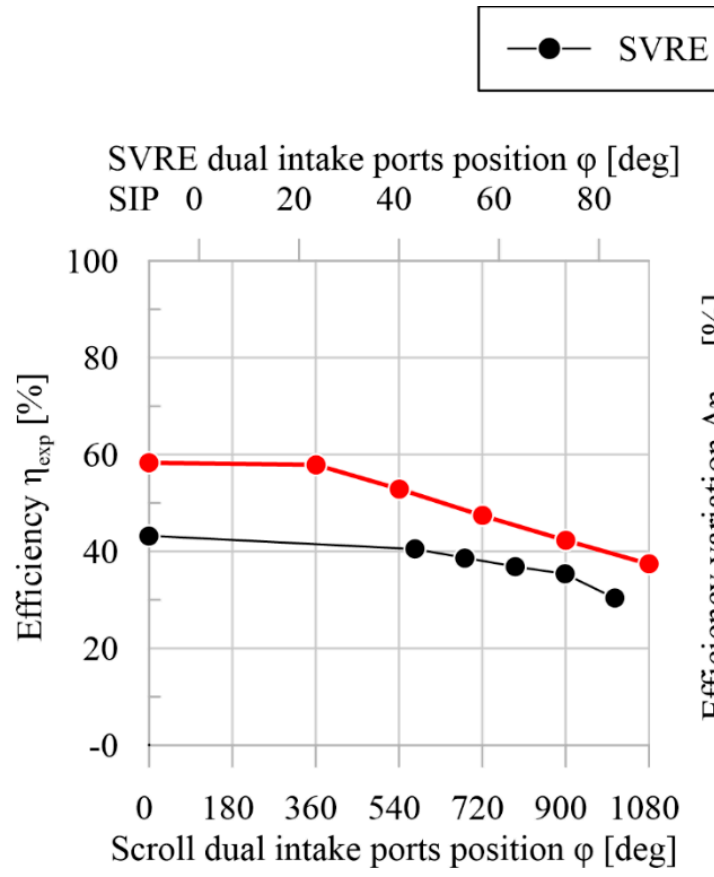

(a)

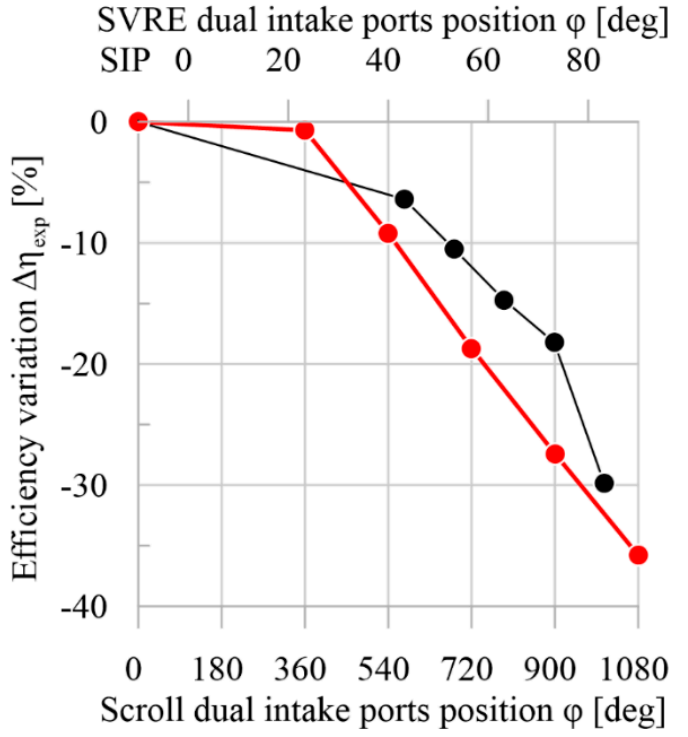

(b)

Figure 15. Efficiency $\eta_{\exp }(\mathbf{a})$ and efficiency variation $\Delta \eta_{\exp }(\mathbf{b})$ induced by DIP in the SVRE and scroll expanders.

\subsection{Discussion}

It can be concluded that the introduction of the DIP leads to a similar fluid-dynamic behavior in both machines (the SVRE and the Scroll). Indeed, the indicated cycle follows the same trend, being the pressure increase in correspondence with the dual intake phase. This leads to the enhancement of the indicated power (i.e., area of $\mathrm{p}-\mathrm{V}$ cycle) and, consequently, of the mechanical power available on the shaft. A further point of contact between the two DIP machines is the fact that the effect of the DIP on expander power diminishes if the angular delay with respect to the main intake port grows.

Concerning the differences between the DIP SVRE and the DIP Scroll, the main difference is that Scroll requires more than one shaft revolution to complete a cycle (intake, expansion and discharge phases), whereas the SVRE completes all the phases in one complete revolution. This means that the dual intake port provides in SVRE the introduction of an extra amount of mass flow rate in lower chamber volumes when compared to the Scroll machine. Therefore, the density in the SVRE decreases less with the increase in volume when compared to the Scroll expander. This leads to a slower reduction of pressure inside the chamber in the SVRE, demonstrated by a more extended isobaric trend in the indicated cycle (Figure 14). The slower reduction of the pressure inside the chamber leads to higher pressure values at the opening of the discharge port, causing a more severe isochoric expansion which produces a higher reduction in global efficiency in the DIP SVRE in comparison to the DIP Scroll. In any case, the isochoric expansion affects power producibility, but it also provides a positive effect on the indicated cycle (Figures 11 and 14).

Considering these results, the introduction of the DIP produces a higher power boost effect on the SVRE (83.3\%) compared to the Scroll (25\%) (Tables 4 and 6). Moreover, the structure of the SVRE is more suitable for hosting the DIP technology, as it is sufficient to make one auxiliary orifice on the casing.

Nevertheless, the adoption of the DIP is also an interesting solution for the Scroll machine in the following respects: 
1. The efficiency of the SIP Scroll expander is higher than that of the SIP SVRE; the further improvement of $25 \%$ of the produced power of the DIP scroll expander is particularly appreciated. Indeed, the DIP technology shows a higher impact on the SVRE power because its original performance is lower than the Scroll expander. This can be seen when the best power configurations of the DIP SVRE $\left(\varphi=53.2^{\circ}\right)$ and the DIP Scroll $\left(\varphi=540^{\circ}\right)$ are observed. Both machines present a comparable power (1491 W for the SVRE and $1410 \mathrm{~W}$ for the Scroll), but the DIP Scroll reaches a higher efficiency than the SVRE (53\% vs. 40\%) (Tables 4 and 6);

2. Another factor which reinforces the suitability of the DIP technology for Scroll expanders is operability. Indeed, SIP scroll expanders are in general characterized by lower permeability compared to SIP SVREs. Thus, high-pressure ratios are achieved for the mass flow rate crossing the machines. With the introduction of the DIP technology, in the optimal configuration, the scroll expanders can elaborate $37 \%$ more mass flow rate with respect the SIP case, widening in this way the operating range of the machine and of the ORC plant.

\section{Conclusions}

Scroll expanders are realistic candidates for small scale ORC-based power units. When these expanders are operated in off-design conditions in terms of working fluid flow rates, an increase of the expander inlet pressure is produced, moving far from optimum behavior also from a thermodynamic point of view. This paper presents a new technology which considers an additional intake port in addition to the main one: the technology has been named the dual-intake-port (DIP). The main feature of this second port is the modification of the permeability of the expander. This allows an increase in the flow rate aspirated by the machine without increasing the expander inlet pressure. Thus, the operability of the expander is increased and its response to off-design conditions significantly improved.

The performances of a DIP Scroll expander was assessed thanks to a detailed physically consistent model of the machine, validated by a set of experimental data from the literature. A good agreement between theoretical and experimental data was obtaine; thus, the model was validated and used as a software platform to assess the feasibility of the so-called DIP technology. The DIP technology was optimized in terms of the position of the second port realized by two orifices: this solution takes into consideration the specificity of the expander, which makes this second working fluid admission far from straightforward. Among different the geometrical possibilities, the paper found an optimum choice for the angular position of the second port, which guarantees an increase close to $25 \%$ of the mechanical power with a corresponding increase of $37 \%$ of the mass flow rate aspirated by the scroll expander, without any effects on the intake expander pressure. On the other hand, the global efficiency of the DIP Scroll expander decreases about 10\% when compared to the single port version, but the benefit of the DIP technology still applies. Indeed, the introduction of dual intake ports ensures that the expander (and consequently the whole unit) can elaborate a higher mass flow rate. This aspect appears to be very interesting, because it is strictly related to the possibility of enhancing the recovery of thermal power at maximum ICE loads. In such a condition, in fact, a single intake port machine is not able to process an increased mass flow rate with respect to the design datum without avoiding a significant expander inlet pressure increase. This means that the DIP allows the operability of the ORC plant to be widened and results in increased mechanical energy recovery.

The performances of the DIP scroll expanders were compared with those of DIP sliding rotary vane expanders (SVREs). DIP technology provides higher effects on power gain in SVREs because they need only one shaft rotation to compete the cycle, whereas the scroll machines take more shaft rotations (five in the case studied). A lower decrease of pressure inside the chambers is therefore produced with respect to what happens inside scroll expanders: in scroll expanders, this causes the overall efficiency to decrease (due to the decrease of the indicated efficiency) when the DIP technology is adopted, despite them having an intrinsically higher efficiency. A maximum 10\% efficiency decrease can 
be achieved via the DIP in scroll expanders by optimizing the position of the second port, but a significant improvement on the power $(+25 \%)$ is obtained this way. In fact, with the adoption of the DIP, the power produced by the expander grows from $1131 \mathrm{~W}$ up to $1410 \mathrm{~W}$ when the angular delay between the main and the secondary intake port is equal to $540^{\circ}$. This power gain is the maximum observed and it is achieved when the pressure difference at the expander sides is $5.6 \mathrm{bar}$ and the pressure and temperature at the intake port are 7 bar and $145.6{ }^{\circ} \mathrm{C}$, respectively. This power benefit is provided by the modification of the permeability of the machine, which allows for an increase in the mass flow rate aspirated $(+37 \%)$. Despite when $\varphi$ is equal to $540^{\circ}$ the maximum DIP power is observed, a reduction of $9.2 \%$ of expander efficiency is noticed with such configuration. For this reason, the best DIP design is the one corresponding to $\varphi$ equal to $360^{\circ}$. Indeed, this DIP position ensures a comparable power gain $(+19.5 \%)$ with a slight efficiency penalization with respect to the SIP machine $(-0.7 \%)$. In conclusion, a significant gain in the operability of the scroll expander is obtained by adopting the DIP technology, which is particularly interesting in the context of recovery units characterized by frequent off-design operating conditions, such as those applied in ICEs for waste heat recovery.

Author Contributions: Conceptualization, F.F., G.D.G. and R.C.; methodology, F.F., G.D.G. and R.C.; software, F.F. and G.D.G.; validation, F.F. and G.D.G.; formal analysis, F.F., G.D.G. and R.C.; investigation, F.F., G.D.G. and R.C.; resources, R.C.; data curation, F.F. and G.D.G.; writing—original draft preparation, F.F., G.D.G. and R.C.; writing-review and editing, F.F., G.D.G. and R.C.; visualization, F.F., G.D.G. and R.C.; supervision, R.C.; project administration, R.C.; funding acquisition, R.C. All authors have read and agreed to the published version of the manuscript.

Funding: This research was funded by the European Project entitled "LONGRUN—Development of efficient and environmental friendly LONG distance powertrain for heavy duty trucks and coaches". Call: H2020-LC-GV-2018-2019-2020, GRANT AGREEMENT NUMBER 874972.

Institutional Review Board Statement: Not applicable.

Informed Consent Statement: Not applicable.

Data Availability Statement: Not applicable.

Acknowledgments: The present research was developed in the framework of the National Operating Program (PON) for Attraction and International Mobility (AIM)-AIM1829299, a project of the Italian Ministry of University (MIUR) to encourage international research collaboration, and of the European Project Development of efficient and environmental friendly LONG distance powertrain for heavy duty trucks and coaches: LONGRUN GRANT AGREEMENT NUMBER 874972.

Conflicts of Interest: The authors declare no conflict of interest.

\section{Nomenclature}

$\begin{array}{ll}\text { Acronyms } & \\ \text { DIP } & \text { Dual intake port } \\ \text { HRVG } & \text { Heat recovery vapor generator } \\ \text { ICE } & \text { Internal combustion engine } \\ \text { RMSE } & \text { Root mean square error } \\ \text { SIP } & \text { Single intake port } \\ \text { SVRE } & \text { Sliding vane rotary expander } \\ \text { WHR } & \text { Waste heat recovery } \\ \text { Symbols } & \\ F_{t} & \text { Friction torque }[\mathrm{Nm}] \\ h & \text { Specific enthalpy }[\mathrm{kJ} / \mathrm{kg}] \\ \dot{m}_{\mathrm{wf}} & \text { Elaborated mass flow rate of working fluid }[\mathrm{kg} / \mathrm{s}] \\ \dot{m}_{\mathrm{vane}} & \text { Mass flow rate of working fluid entering the chamber }[\mathrm{kg} / \mathrm{s}] \\ \dot{m}_{\text {leak }} & \text { Leakages mass flow rate }[\mathrm{kg} / \mathrm{s}] \\ n_{c} & \text { Number of scroll revolution in a cycle } \\ P & \text { Power }[\mathrm{W}]\end{array}$




$\begin{array}{ll}p & \text { Pressure [Pa], [bar] } \\ T & \text { Temperature }[\mathrm{K}]-\left[{ }^{\circ} \mathrm{C}\right] \\ V & \text { Chamber volume }\left[\mathrm{cm}^{3}\right] \\ \begin{array}{l}\text { Subscripts } \\ \text { cycle }\end{array} & \text { rotation cycle } \\ \text { exp } & \text { expander global efficiency } \\ \text { in } & \text { inlet } \\ \text { ind } & \text { indicated } \\ \text { is } & \text { isentropic condition } \\ \text { loss } & \text { power loss due to friction } \\ \text { mech } & \text { mechanical } \\ \text { out } & \text { outlet } \\ \text { vol } & \text { volumetric } \\ \text { WF } & \text { working fluid } \\ \text { Greek symbols } & \\ \alpha & \text { scroll permeability [kg/(s·MPa)] } \\ \eta & \text { efficiency } \\ \mu & \text { dynamic viscosity [Pa·s] } \\ \theta & \text { revolution angle [deg] } \\ \varphi & \text { angular delay of DIP with respect main intake port [deg] } \\ \omega & \text { revolution speed [RPM]-[RPS] }\end{array}$

\section{References}

1. Transport Emissions. Available online: https:/ / ec.europa.eu/clima/eu-action/transport-emissions_en (accessed on 16 November 2021).

2. European Automobile Manufacturers' Association (ACEA). Paving the Way to Carbon-Neutral Transport 10-Point Plan to Help Implement the European Green Deal. 2020. Available online: https://www.acea.auto/files/ACEA_10-point_plan_European_ Green_Deal.pdf (accessed on 16 November 2021).

3. European Union. Regulation (EU) 2019/631 of the European Parliament and of the Council. Off. J. Eur. Union 2019, 1-50.

4. Serrano, J.R.; Novella, R.; Piqueras, P. Why the development of internal combustion engines is still necessary to fight against global climate change from the perspective of transportation. Appl. Sci. 2019, 9, 4597. [CrossRef]

5. Seyedkavoosi, S.; Javan, S.; Kota, K. Exergy-based optimization of an organic Rankine cycle (ORC) for waste heat recovery from an internal combustion engine (ICE). Appl. Therm. Eng. 2017, 126, 447-457. [CrossRef]

6. Song, J.; Li, X.; Wang, K.; Markides, C.N. Parametric optimisation of a combined supercritical CO2 (S-CO2) cycle and organic Rankine cycle (ORC) system for internal combustion engine (ICE) waste-heat recovery. Energy Convers. Manag. 2020, 218 , 112999. [CrossRef]

7. Shi, L.; Shu, G.; Tian, H.; Deng, S. A review of modified Organic Rankine cycles (ORCs) for internal combustion engine waste heat recovery (ICE-WHR). Renew. Sustain. Energy Rev. 2018, 92, 95-110. [CrossRef]

8. Di Battista, D.; Di Bartolomeo, M.; Villante, C.; Cipollone, R. On the limiting factors of the waste heat recovery via ORC-based power units for on-the-road transportation sector. Energy Convers. Manag. 2018, 155, 68-77. [CrossRef]

9. Chatzopoulou, M.A.; Simpson, M.; Sapin, P.; Markides, C.N. Off-design optimisation of organic Rankine cycle (ORC) engines with piston expanders for medium-scale combined heat and power applications. Appl. Energy 2019, 238, 1211-1236. [CrossRef]

10. Marchionni, M.; Bianchi, G.; Karvountzis-Kontakiotis, A.; Pesyridis, A.; Tassou, S.A. An appraisal of proportional integral control strategies for small scale waste heat to power conversion units based on Organic Rankine Cycles. Energy 2018, 163, $1062-1076$. [CrossRef]

11. Chatzopoulou, M.A.; Lecompte, S.; de Paepe, M.; Markides, C.N. Off-design optimisation of organic Rankine cycle (ORC) engines with different heat exchangers and volumetric expanders in waste heat recovery applications. Appl. Energy 2019, $253,113442$. [CrossRef]

12. Moradi, R.; Villarini, M.; Cioccolanti, L. Experimental modeling of a lubricated, open drive scroll expander for micro-scale organic Rankine cycle systems. Appl. Therm. Eng. 2021, 190, 116784. [CrossRef]

13. Pantano, F.; Capata, R. Expander selection for an on board ORC energy recovery system. Energy 2017, 141, 1084-1096. [CrossRef]

14. Dumont, O.; Parthoens, A.; Dickes, R.; Lemort, V. Experimental investigation and optimal performance assessment of four volumetric expanders (scroll, screw, piston and roots) tested in a small-scale organic Rankine cycle system. Energy 2018, 165, 1119-1127. [CrossRef]

15. Bao, J.; Zhao, L. A review of working fluid and expander selections for organic Rankine cycle. Renew. Sustain. Energy Rev. 2013, 24, 325-342. [CrossRef]

16. Imran, M.; Usman, M.; Park, B.S.; Lee, D.H. Volumetric expanders for low grade heat and waste heat recovery applications. Renew. Sustain. Energy Rev. 2016, 57, 1090-1109. [CrossRef] 
17. Song, P.; Wei, M.; Shi, L.; Danish, S.N.; Ma, C. A review of scroll expanders for organic rankine cycle systems. Appl. Therm. Eng. 2015, 75, 54-64. [CrossRef]

18. Chang, J.C.; Chang, C.W.; Hung, T.C.; Lin, J.R.; Huang, K.C. Experimental study and CFD approach for scroll type expander used in low-temperature organic Rankine cycle. Appl. Therm. Eng. 2014, 73, 1444-1452. [CrossRef]

19. Emhardt, S.; Tian, G.; Song, P.; Chew, J.; Wei, M. CFD modelling of small scale ORC scroll expanders using variable wall thicknesses. Energy 2020, 199, 117399. [CrossRef]

20. Zhang, X.; Xu, Y.; Xu, J.; Sheng, Y.; Zuo, Z.; Liu, J.; Chen, H.; Wang, Y.; Huang, Y. Study on the performance and optimization of a scroll expander driven by compressed air. Appl. Energy 2017, 186, 347-358. [CrossRef]

21. Lemort, V.; Quoilin, S.; Cuevas, C.; Lebrun, J. Testing and modeling a scroll expander integrated into an Organic Rankine Cycle. Appl. Therm. Eng. 2009, 29, 3094-3102. [CrossRef]

22. Kutlu, C.; Erdinc, M.T.; Li, J.; Su, Y.; Pei, G.; Gao, G.; Riffat, S. Evaluate the validity of the empirical correlations of clearance and friction coefficients to improve a scroll expander semi-empirical model. Energy 2020, 202, 117723. [CrossRef]

23. Song, P.; Wei, M.; Zhang, Y.; Sun, L.; Emhardt, S.; Zhuge, W. The impact of a bilateral symmetric discharge structure on the performance of a scroll expander for ORC power generation system. Energy 2018, 158, 458-470. [CrossRef]

24. Kosmadakis, G.; Mousmoulis, G.; Manolakos, D.; Anagnostopoulos, I.; Papadakis, G.; Papantonis, D. Development of Open-Drive Scroll Expander for an Organic Rankine Cycle (ORC) Engine and First Test Results. Energy Procedia 2017, 129, 371-378. [CrossRef]

25. Ziviani, D.; James, N.A.; Accorsi, F.A.; Braun, J.E.; Groll, E.A. Experimental and numerical analyses of a 5 kWe oil-free open-drive scroll expander for small-scale organic Rankine cycle (ORC) applications. Appl. Energy 2018, 230, 1140-1156. [CrossRef]

26. Garg, P.; Karthik, G.M.; Kumar, P.; Kumar, P. Development of a generic tool to design scroll expanders for ORC applications. Appl. Therm. Eng. 2016, 109, 878-888. [CrossRef]

27. Yang, J.; Sun, Z.; Yu, B.; Chen, J. Modeling and optimization criteria of scroll expander integrated into organic Rankine cycle for comparison of R1233zd(E) as an alternative to R245fa. Appl. Therm. Eng. 2018, 141, 386-393. [CrossRef]

28. Emhardt, S.; Tian, G.; Chew, J. A review of scroll expander geometries and their performance. Appl. Therm. Eng. 2018, 141, 1020-1034. [CrossRef]

29. Emhardt, S.; Tian, G.; Song, P.; Chew, J.; Wei, M. CFD analysis of the influence of variable wall thickness on the aerodynamic performance of small scale ORC scroll expanders. Energy 2021, 122586. [CrossRef]

30. Emhardt, S.; Song, P.; Tian, G.; Chew, J.; Wei, M. CFD analysis of variable wall thickness scroll expander integrated into small scale ORC systems. Energy Procedia 2019, 158, 2272-2277. [CrossRef]

31. Fatigati, F.; Di Bartolomeo, M.; Cipollone, R. Dual intake rotary vane expander technology: Experimental and theoretical assessment. Energy Convers. Manag. 2019, 186, 156-167. [CrossRef]

32. Fatigati, F.; Di Bartolomeo, M.; Di Battista, D.; Cipollone, R. A dual-intake-port technology as a design option for a Sliding Vane Rotary Expander of small-scale ORC-based power units. Energy Convers. Manag. 2020, 209, 112646. [CrossRef]

33. Fatigati, F.; Di Giovine, G.; Cipollone, R. Model-based characterization of a dual intake-port scroll expander operating in an ORC-based power unit. In Proceedings of the 16th Conference on Sustainable Development of Energy, Water and Environment Systems, Dubrovnik, Croatia, 10-15 October 2021; pp. 1-21.

34. Mudrovčić, A.; Ban, M. Book of Abstracts - 16th Conference on Sustainable Development of Energy, Water and Environment Systems; Faculty of Mechanical Engineering and Naval Architecture, Zagreb: Dubrovnik, Croatia, 2021.

35. Lemort, V. Contribution to the Characterization of Scroll Machines in Compressor and Expander Modes. Ph.D. Thesis, University of Liège, Liège, Belgium, 2008.

36. Chen, Y.; Halm, N.P.; Groll, E.A.; Braun, J.E. Mathematical modeling of scroll compressors—Part I: Compression process modeling Int. J. Refrig. 2002, 25, 731-750. [CrossRef]

37. Chen, Y.C.; Halm, N.P.; Braun, J.E.; Groll, E.A. Mathematical modeling of scroll compressors—Part II: Overall scroll compressor modeling. Int. J. Refrig. 2002, 25, 751-764. [CrossRef]

38. Sun, S.; Wu, K.; Guo, P.; Yan, J. Analysis of the three-dimensional transient flow in a scroll refrigeration compressor. Appl. Therm. Eng. 2017, 127, 1086-1094. [CrossRef]

39. Quoilin, S.; Lemort, V.; Lebrun, J. Experimental study and modeling of an Organic Rankine Cycle using scroll expander. Appl. Energy 2010, 87, 1260-1268. [CrossRef]

40. Gamma Technologies. Flow Theory Manual-GT-SUITE ${ }^{\mathrm{TM}}$. 2012. Available online: https://www.gtisoft.com/ (accessed on 8 December 2021). 